\title{
DNA double-strand break repair in Caenorhabditis elegans
}

\author{
Bennie B. L. G. Lemmens • Marcel Tijsterman
}

Received: 3 May 2010 /Revised: 14 October 2010 / Accepted: 15 October 2010 /Published online: 5 November 2010

(C) The Author(s) 2010. This article is published with open access at Springerlink.com

\begin{abstract}
Faithful repair of DNA double-strand breaks (DSBs) is vital for animal development, as inappropriate repair can cause gross chromosomal alterations that result in cellular dysfunction, ultimately leading to cancer, or cell death. Correct processing of DSBs is not only essential for maintaining genomic integrity, but is also required in developmental programs, such as gametogenesis, in which DSBs are deliberately generated. Accordingly, DSB repair deficiencies are associated with various developmental disorders including cancer predisposition and infertility. To avoid this threat, cells are equipped with an elaborate and evolutionarily well-conserved network of DSB repair pathways. In recent years, Caenorhabditis elegans has become a successful model system in which to study DSB repair, leading to important insights in this process during animal development. This review will discuss the major contributions and recent progress in the C. elegans field to elucidate the complex networks involved in DSB repair, the impact of which extends well beyond the nematode phylum.
\end{abstract}

\section{Introduction}

DNA double-strand breaks and development

Genomes are constantly attacked by DNA damaging agents, such as endogenous cellular metabolites, exogenous

Communicated by E. Nigg

B. B. L. G. Lemmens • M. Tijsterman $(\bowtie)$

Department of Toxicogenetics, Leids Universitair Medisch

Centrum Gebouw 2,

Postzone S-4 Postbus 9600, Einthovenweg 20,

2333 ZC Leiden, The Netherlands

e-mail: m.tijsterman@lumc.nl genotoxins, and radiation. Moreover, genomes are continuously challenged by mutagenic processes, such as transposition and imperfect replication. All of these sources of DNA damage generate a vast amount of DNA lesions, among which single-strand DNA lesions (SSLs) are the most common. It is estimated that, in normal human cells, approximately $1 \%$ of endogenous SSLs are converted into roughly 50 DNA double-strand breaks (DSBs) per cell per cell cycle (Vilenchik and Knudson 2006), which pose a serious threat to all proliferating cells. DSBs are the most toxic forms of DNA damage, as a single DSB has the potential to activate cell cycle arrest and can be lethal to a cell if left unrepaired (Bennett et al. 1993). Improper repair of DSBs can also lead to large deletions and gross chromosomal rearrangements, which ultimately result in cellular dysfunction. However, some cells deliberately inflict DSBs to induce genetic variation, as seen in budding yeast during mating-type switching, in lymphocytes during $\mathrm{V}(\mathrm{D}) \mathrm{J}$ recombination, and in sexually reproducing organisms during meiosis. In fact, during meiosis, DSB repair products establish transient physical links between chromosomes that are essential for proper chromosome segregation.

Although mutations can be beneficial on an evolutionary scale, faithful repair of all types of lesions is vital to ensure genomic stability and is therefore fundamental to the fitness of a cell and the reproductive success of a species. As a result, multiple DSB repair pathways have evolved to handle this inevitable and constant threat.

The DSB repair network

In human cells, most DSBs are repaired via a conserved pathway called non-homologous end joining (NHEJ), which is an error-prone pathway that readily joins broken 
DNA ends together independent of sequence context (Fig. 1; Lieber 2010). In addition, mutagenic repair pathways called single-strand annealing (SSA) and micro-homologymediated end joining (MMEJ) use long (30-400 bp) or short (5-15 bp) sequences of homology flanking the DSB to anneal and re-ligate the DSB ends, respectively (McVey and Lee 2008; Sugawara et al. 2000). DSBs can also be repaired via homologous recombination (HR), a high-fidelity repair route that uses an undamaged homologous DNA template from a sister chromatid or homologous chromosome to restore the sequence information lost at the break site (Fig. 1; Li and Heyer 2008). These DSB repair pathways form a complex network to safeguard genome integrity, operating in both competitive and collaborative manners, depending on the repair context, stage of the cell cycle, and state of the broken DNA. In the last 30 years, many genes involved in these DSB repair pathways have been identified and many of them have been implicated in severe disorders (i.e., cancer predisposition syndromes and premature aging) (Hoeijmakers 2009; Fig. 2).
Caenorhabditis elegans as a DSB repair model

In 1974, Sydney Brenner launched a new animal model: a small transparent nematode called $C$. elegans, which proved to be very convenient to study developmental processes, including cell death and differentiation (Brenner 1974; Hoffenberg 2003; Horvitz 2003; Sulston 2003). Soon after, the entire C. elegans genome was sequenced in 1998, its potential to contribute to our understanding of DSB repair was appreciated, as this model organism has allowed in-depth analysis of known DSB repair genes (e.g., Adamo et al. 2008; Alpi et al. 2003; Chin and Villeneuve 2001; Zalevsky et al. 1999), but has also permitted efficient forward genetic screens (Kelly et al. 2000; Winand et al. 1998) as well as high-throughput reverse genetic screens (Pothof et al. 2003; van Haaften et al. 2006) to identify novel DSB response factors. For some of these novel genes, a role in DSB repair has recently been demonstrated for their cognate human ortholog (Smeenk et al. 2010; Polo et al. 2010; H. van Attikum personal communication).

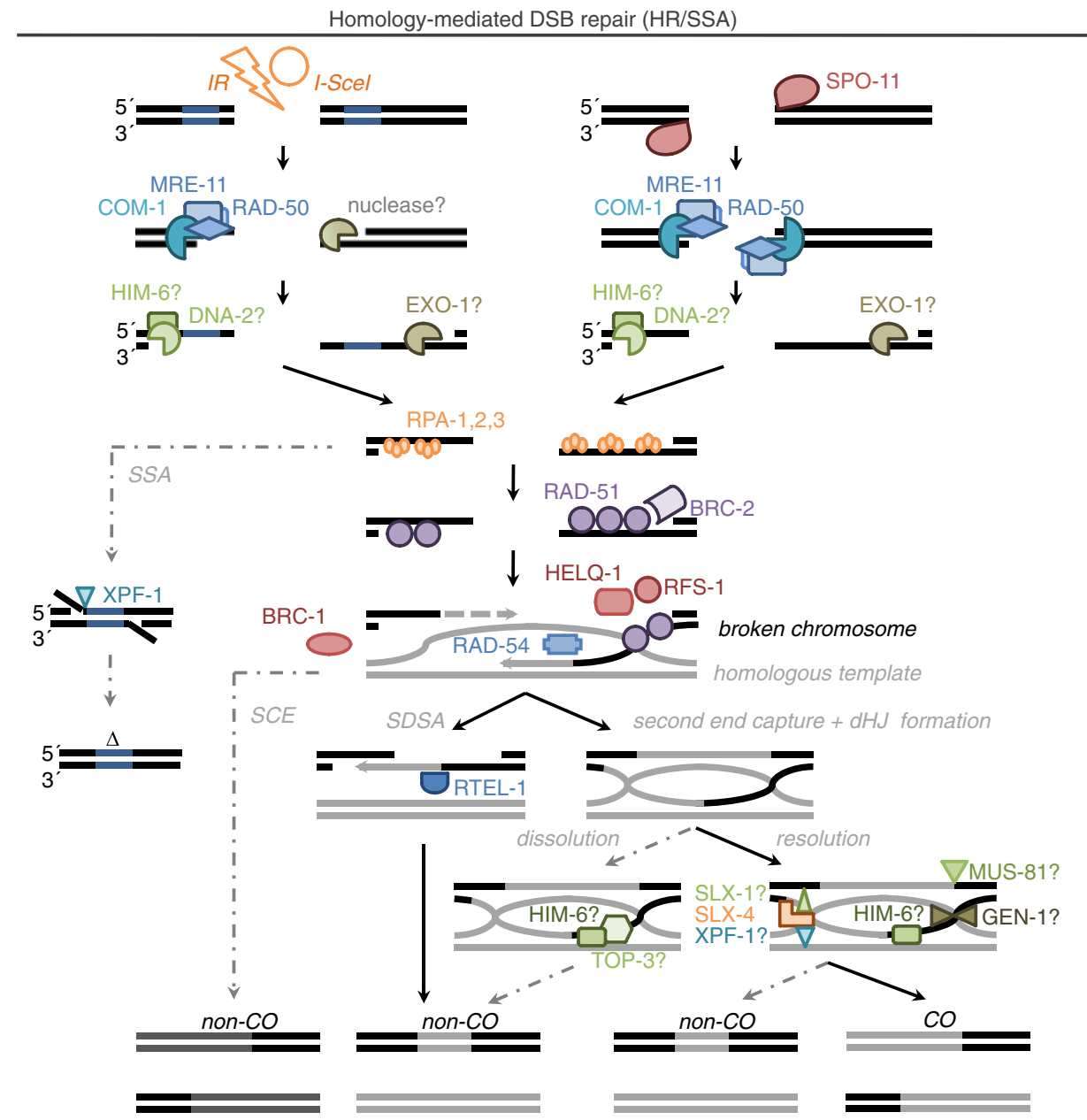

Fig. 1 Schematic overview of DSB repair pathways in C. elegans. See text for details. SSA single-strand annealing, $S C E$ sister chromatid exchange, SDSA synthesis-dependent strand annealing 


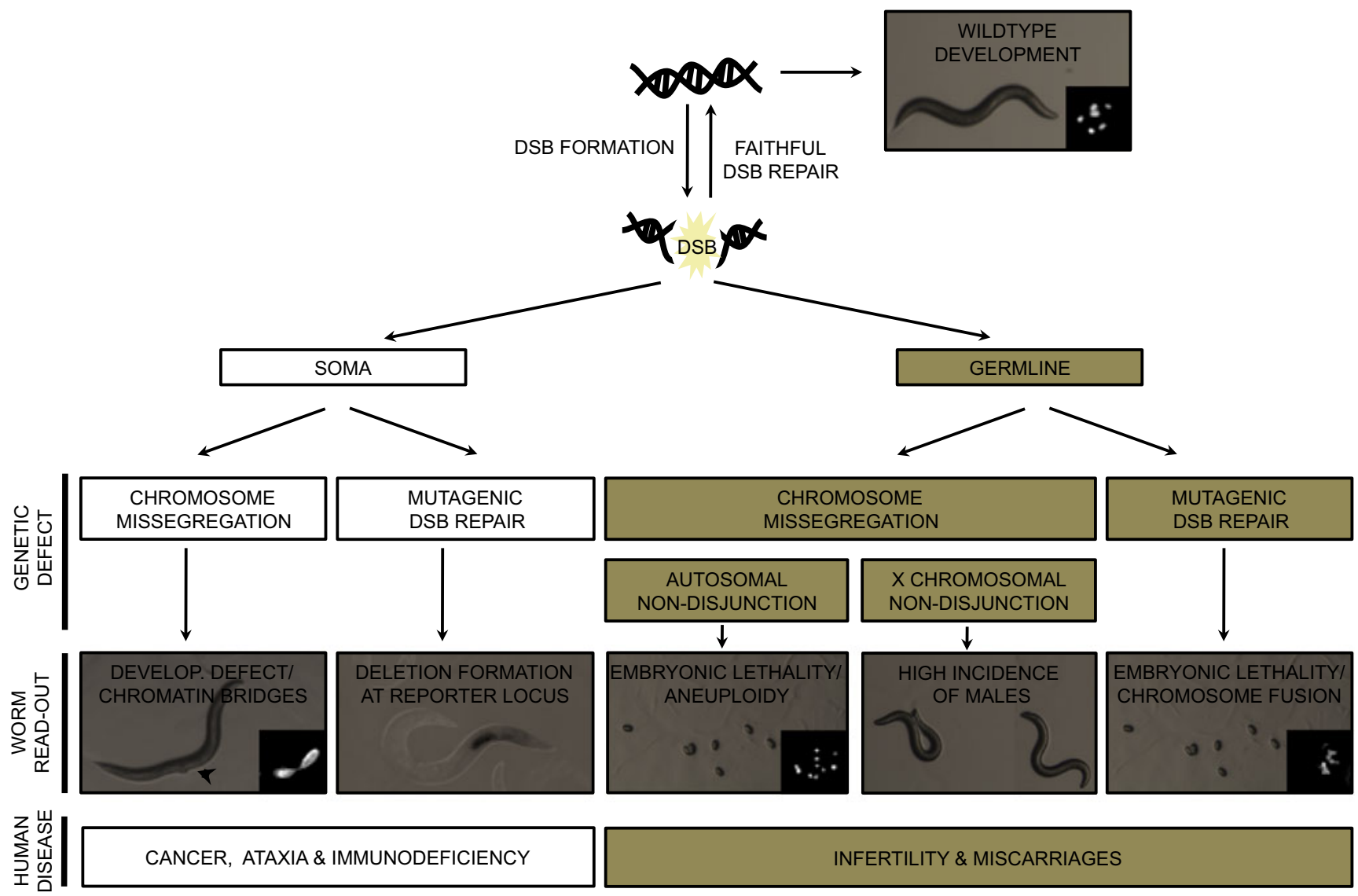

Fig. 2 Consequences of faulty DSB repair in C. elegans and humans. DSB repair defects result in the accumulation of DSBs, which ultimately will result in genetic defects. Depending on the cell type in which the genetic defects occur (germline or soma), distinct developmental abnormalities become apparent. In the C. elegans field, these phenotypes are often used as readouts for specific forms of genomic instability, allowing researchers to delineate developmental

Because DSBs can be repaired via distinct pathways, each consisting of numerous factors, mutations in individual DSB repair genes can have very different consequences. For example, some DSB repair defects result in frequent gross chromosomal aberrations (leading to developmental retardation or even embryonic death), while others only induce a minor shift towards efficient but error-prone repair modes (ultimately driving the accumulation of mutations and resulting in associated diseases such as cancer; Fig. 2). In worms, both erroneous DSB repair and chromosomal instability often result in developmental abnormalities, altered chromosome morphology, and/or DNA damage sensitivity, all of which are phenotypes that can be readily detected without the need of complex techniques (Fig. 2). Furthermore, elevated chromosomal instability in the germline often manifests as increased $\mathrm{X}$ chromosome non-disjunction, which in $C$. elegans results in an overrepresentation of males (X0) in the otherwise hermaphrodite (XX)-dominated population (Fig. 2). This so- consequences of known DSB repair defects, and also to screen for novel DSB repair factors. Often-used genomic instability readouts are: embryonic viability, frequency of X0 males, nuclear morphology of diakinesis/intestinal nuclei (insets), occurrence of vulval defects, and transgenic reporter readouts. Notably, the genetic defects underlying these phenotypes are strongly associated with severe diseases in humans, including DSB repair deficiency disorders

called high-incidence-of-males (Him) phenotype has proved to be a convenient readout and has revealed several DSB repair factors that are crucial to proper meiotic progression (Kelly et al. 2000; Tang et al. 2010). Unique features such as an invariant cell lineage, the linear array of meiotic stages along the hermaphrodite gonad, and easy knockdown via systemic RNAi make this multicellular animal a suitable model in which to study DSB repair in the context of somatic as well as germline tissues (Figs. 2 and 3).

In addition to many repair pathways, the damage response to DSBs also encompasses an elaborate signaling network that regulates cell cycle checkpoint arrest and/or apoptosis. In recent years, comprehensive overviews have been published on the latter two aspects of the DNA damage response in C. elegans (O'Neil and Rose 2006; Gartner et al. 2008). Here, we will discuss the major contributions and recent progress in the $C$. elegans field to elucidate the complex networks involved in DSB repair. In 


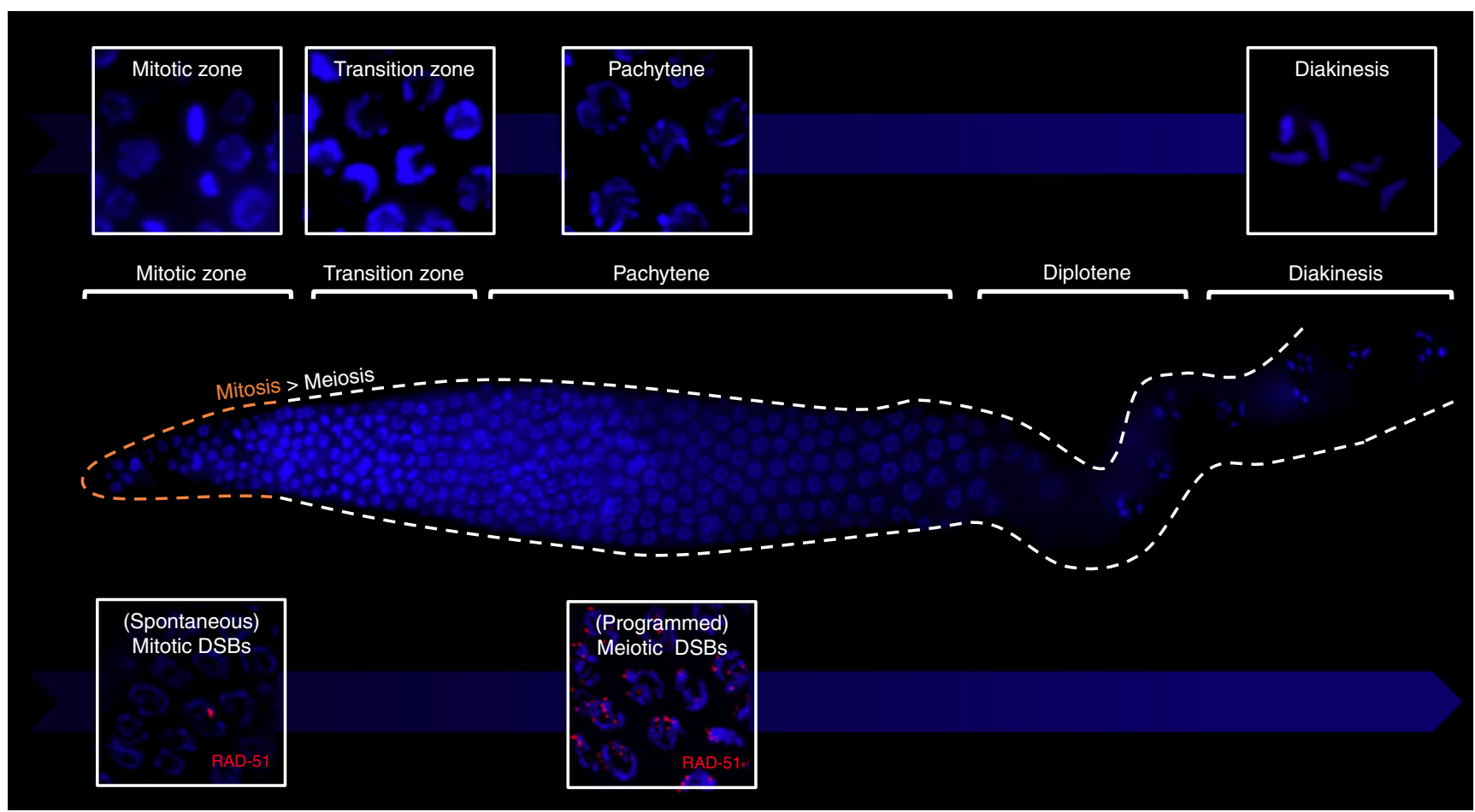

Fig. 3 Visualization of DSB repair in the adult germline. Representative image of a dissected DAPI-stained wild-type C. elegans germline. The convenient spatio-temporal organization of meiotic prophase, paralleled by dynamic changes in chromosome organization

the first part, we will discuss the regulation and repair of (programmed) DSBs in the worm germline, and in the second part, we will focus on DSB repair in somatic cells.

\section{DSB repair during meiosis}

Meiosis and the worm germline

Perhaps the most important biological process that involves the deliberate generation and repair of DSBs is the specialized cell division program of meiosis. In brief, meiosis enables diploid germ cells to produce haploid gametes. The primary function of meiosis is to reduce the chromosome complement by half, which is achieved by having a single round of DNA replication followed by two subsequent rounds of chromosome segregation (named meiosis I and meiosis II). In C. elegans, mitotically proliferating germ cell nuclei reside at the distal end of the gonadal syncitium, in the so-called "mitotic zone". As these nuclei move to the proximal end of the germline, they progress through different meiotic stages (Figs. 3 and 5). First, nuclei enter a "transition zone", where meiosis I begins and maternal and paternal versions of each chromosome (homologous chromosomes) pair and align. Around this time, several DSBs are introduced by a highly (upper panel), allow in-depth analysis of chromosomal stability during gametogenesis, including HR-mediated DSB repair events typified by RAD-51 recruitment (lower panel)

conserved topoisomerase-like endonuclease called SPO11, and HR is initiated to repair the SPO-11-induced DSBs (Dernburg et al. 1998; Keeney and Neale 2006). As the nuclei enter the "pachytene zone", a proteinaceous structure known as the synaptonemal complex (SC) is assembled to temporarily keep the homologous chromosomes in close proximity to each other, a process called synapsis. Meanwhile, a specific set of HR events between the homologous chromosomes result in repair products known as crossovers (COs). These COs (together with sister chromatid cohesion) generate the transient physical links, called chiasmata, that physically connect the homologous chromosomes and allow the homologs to separate adequately during the first meiotic division. During the "diplotene stage", the chromosomes desynapse, but remain condensed and are held together by the chiasmata. At the "diakinesis stage", the pairs of homologous chromosomes can be easily identified in the maturing oocyte as six discrete bivalents (Fig. 3). As soon as the oocyte is fertilized in the spermatheca, meiotic spindles are formed and the homologous chromosomes are separated during anaphase I. After one set of chromosomes has been excluded (a process called polar body extrusion), meiosis II starts and the other chromosomes align at the spindle equator. In anaphase II, the sister chromatids are separated and again, one set is excluded. As meiosis completes, six 
chromosomes remain and form the oocyte pronucleus, which together with the sperm-derived pronucleus contains all the genetic information necessary for the development of a new individual.

The chiasmata are crucial for the homologs to correctly orient toward opposite spindle poles during anaphase I. Therefore, the induction and resolution of chiasmata is critical for faithful chromosome segregation, as is illustrated by the fact that worms that are unable to introduce meiotic DSBs (e.g., spo-11 mutants) produce hardly any viable offspring, due to excessive aneuploidy (Dernburg et al. 1998), whereas worms that cannot repair the SPO-11induced DSBs (e.g., HR defective rad-51 mutants) produce no viable progeny at all (Alpi et al. 2003). In addition to their essential role in chromosome dynamics, meiotic DSBs are also the sites of genetic exchange between the broken chromosome and its repair template, either the sister chromatid or homologous chromosome. In the case of the latter, CO-mediated DSB repair leads to the exchange of large sections between the paternal and maternal chromosome. Therefore, the choice between non-CO or CO-mediated DSB repair has a significant impact on the genetic variation within a species. Meiotic DSB repair needs thus to be accurate in order to safeguard genomic stability, but also needs to allow genetic changes that can result in evolutionary benefits.

\section{Synapsis and meiotic DSB repair}

The repair of SPO-11-induced DSBs is a complex multistep process that is accompanied by dynamic changes in chromosome architecture. HR is the principal mode of meiotic DSB repair in C. elegans (Clejan et al. 2006; Martin et al. 2005) and requires a homologous template: either the sister chromatid (always resulting in non-CO) or the homologous chromosome (resulting in either non-CO or $\mathrm{CO}$ ). Because chromosome structure affects the availability of these substrates, several protein complexes involved in meiotic chromosome organization have been shown to affect DSB repair outcome. Mutation of SC genes hampers the ability of homologous chromosomes to stay in close juxtaposition at the moment when the meiotic DSBs are repaired, and accordingly, these mutations lead to a severe reduction in CO recombination (Colaiacovo et al. 2003; Couteau et al. 2004; Garcia-Muse and Boulton 2007; Goodyer et al. 2008; Smolikov et al. 2007; Zetka et al. 1999). However, synapsis mutants generally have no defects in SPO-11-mediated DSB induction, and the majority of DSBs are ultimately repaired. For instance, synapsis does not occur in syp-2 mutants, but RAD-51 foci (as markers for DSB repair intermediates) disappear late in meiotic prophase, implying that meiotic DSBs are repaired eventually, likely via error-free HR using the sister chromatid as a template (Colaiacovo et al. 2003). Instead of six bivalents, syp-2 mutants have 12 intact univalents at diakinesis, indicative of a lack of $\mathrm{CO}$ formation and chiasmata establishment (Colaiacovo et al. 2003). Indeed, when inter-sister HR is inhibited in such a synapsis defective background (either via $b r c-1$ mutation, rad-51, or rec-8 RNAi), faithful meiotic DSB repair is impaired, leading to severe chromosomal fragmentation (Adamo et al. 2008; Colaiacovo et al. 2003; Smolikov et al. 2007). Although the majority of SC factors likely affect meiotic DSB repair indirectly, by controlling repair template availability, some structural components of the SC seem to affect meiotic DSB repair in a more direct fashion. For example, the axial SC components HTP-1 and HIM-3 have been shown to prevent inter-sister HR and are therefore crucial for the inter-homolog bias during meiotic recombination and subsequent $\mathrm{CO}$ formation in early prophase (Couteau et al. 2004; Martinez-Perez and Villeneuve 2005).

Whereas homologous chromosomes are temporarily held together via the SC, sister chromatids are held together by cohesin complexes. Meiosis-specific cohesin components have been implicated in meiotic DSB repair efficacy (Pasierbek et al. 2001). Recently, Severson and colleagues have studied the consequences of a complete absence of sister chromatid cohesion (SCC) on genome integrity. They showed that mutation of the general cohesin component SMC-1 or simultaneous depletion of meiotic cohesin subunits REC-8, COH-3, and COH-4 results in discrete chromosomal fragments in diakinesis nuclei (Severson et al. 2009). Lack of SCC eradicates the availability of all DNA templates needed for HR, blocking both inter-sister and inter-homolog HR. Interestingly, direct inactivation of HR (via rad-51, brc-2, or rad-54 mutation) does not lead to persistent DSBs and fragmented chromosomes, but instead provokes inaccurate DSB repair, resulting in irregular chromatin aggregates at diakinesis (Martin et al. 2005; Ward et al. 2010). Chromosome aggregation in rad-51 and brc-2 mutants has been shown to (partially) depend on canonical NHEJ factors, which are apparently able to act on meiotic DSBs under these conditions (Martin et al. 2005). These diakinesis phenotypes clearly contrast those observed in SSC deficient germlines, in which the DSBs seem to persist and undergo no repair at all (Adamo et al. 2008; Svendsen et al. 2009). A question that follows from these observations is: why do defects in HR allow other repair pathways, such as NHEJ, to take over, while the unavailability of a proper HR template does not?

\section{Synapsis and meiotic DSB formation}

In yeast, plants, and mammals, meiotic DSBs are not only important for $\mathrm{CO} /$ chiasmata formation; they are also required for the processes of $\mathrm{SC}$ formation and synapsis 
itself (Zickler 2006). Such a link between DSB formation and chromosome organization was thought to be absent in worms and flies, as synapsis can occur normally in spo-11 mutants in these model species (Dernburg et al. 1998). However, more nuances to this view was provided recently by Smolikov and colleagues, who identified $\mathrm{cra}-1$ as a regulator of SC assembly and showed that, in the absence of cra-1, HR-mediated repair of meiotic DSBs was needed for the proper recruitment and polymerization of SC components (Smolikov et al. 2008).

Another possible link between DSB formation and synapsis came from investigating a unique meiotic axis component called HTP-3, which was shown to have a dual role during meiosis, being required for synapsis as well as meiotic DSB formation (Goodyer et al. 2008). HTP-3 interacts with HIM-3, one of the above-mentioned SC components controlling synapsis and sister chromatid exchange (SCE). Interestingly, HTP-3 also formed a complex with two members of the so-called Mre11Rad50-Nbs1 (MRN) complex. The MRN complex is required for Spo11-mediated DSB formation in yeast and is implicated in several DSB repair pathways (Johzuka and Ogawa 1995; Rupnik et al. 2010). In line with a role in DSB formation, both $h t p-3$ and MRN-deficient worms resemble spo-11 mutants, as their germlines lack RAD-51 foci in early pachytene and typically show 12 intact univalents at diakinesis. Furthermore, similar to spo-11 mutation, both $h t p-3$ and MRN mutations can rescue the DSB-dependent chromosomal aggregation observed in RAD-51 depleted germlines (Chin and Villeneuve 2001; Goodyer et al. 2008; Hayashi et al. 2007). However, artificially induced DSBs can rescue CO formation in spo-11 mutants, but not in htp-3 mutants, revealing an additional role for HTP-3 downstream of meiotic DSB formation. Recently, HTP-3 has been shown to be critical for the chromosomal association of HIM-3 as well as several other SC components and the cohesion factor REC-8, making it a crucial factor for meiotic chromosome axis organization and a prerequisite for proper meiotic DSB induction and subsequent $\mathrm{CO}$ formation (Goodyer et al. 2008; Severson et al. 2009).

Chromosome structure and meiotic DSB formation

In recent years, additional factors altering chromosome structure have been shown to coordinate meiotic DSB formation. The Villeneuve lab identified HIM-17, a chromatin-associated protein that is essential for meiotic DSB induction, but in contrast to HTP-3, is dispensable for synapsis. him-17 mutants resemble spo-11 mutants by showing no RAD-51 foci in early pachytene and no chiasmata at diakinesis (Reddy and Villeneuve 2004). Both phenotypes can be restored by artificially induced DSBs, confirming a specific role for HIM-17 in DSB induction.
Intriguingly, him-17 mutant germlines also displayed altered patterns of histone $\mathrm{H} 3$ methylation, which could suggest that chromatin modification contributes to the competence for initiation of meiotic recombination.

Recently, the Meyer lab discovered an additional link between chromosome structure and meiotic DSB induction. They revealed a novel role for condensin complexes in controlling chromosome structure and meiotic DSB formation. Using elegant tools, including a terminal deoxynucleotidyl transferase mediated dUTP nick-end-labeling (TUNEL) assay that enabled them to label $3^{\prime}$ ends of meiotic DSBs, they demonstrated that $\mathrm{CO}$ number and $\mathrm{CO}$ distribution are controlled on a chromosome-wide basis at the level of DSB formation by a condensin complex (Mets and Meyer 2009). Specifically, lack of the condensin subunit DPY-28 led to a remarkable expansion of the axis of meiotic chromosomes, which was paralleled by an elevated number of DSBs and altered CO distribution (Mets and Meyer 2009; Tsai et al. 2008), suggesting that specific condensins limit DSB formation by controlling chromosome organization. Reinforcing this view, $d p y-28$ mutations partially restored DSB formation in him-17 mutants (Tsai et al. 2008). Vice versa, the restored DSB formation in $d p y-28 / \mathrm{him}-17$ double mutants argues for the hypothesis that HIM-17 promotes meiotic DSB formation by influencing chromatin structure.

\section{Meiotic DSB induction and CO formation}

Using the TUNEL assay and mutants that trapped RAD-51 (a marker for HR intermediates) at the break sites, Mets and Meyer assessed the number of DSBs inflicted during normal meiosis (Mets and Meyer 2009). Their data suggests that meiotic nuclei encounter approximately 10-12 DSBs in C. elegans, which is surprisingly low, considering that each of the six chromosome pairs needs at least one DSB to be able to form the obligate $\mathrm{CO} /$ chiasmata. This finding implies the existence of a surveillance mechanism that ensures that at least one half of the DSBs are repaired via a $\mathrm{CO}$ intermediate. Moreover, these COs should be distributed over the genome such that every homolog pair has at least one $\mathrm{CO}$ and that the $\mathrm{COs}$ do not occur in close proximity to each other (phenomena referred to as "CO homeostasis" and "CO interference", respectively). The degree of interference and the number of COs per meiosis vary between organisms. In $C$. elegans, $\mathrm{CO}$ interference is absolute, such that each chromosome pair undergoes only a single CO (Hillers and Villeneuve 2003; Wood 1988). CO interference is also reported in budding yeast, which has 16 chromosomes and 150-200 DSBs per meiosis (Buhler et al. 2007). Similar to the nematode, one half of the DSBs are converted into COs, in this case, resulting in approximately five crossovers per homolog pair (Mortimer et al. 1992). In contrast, CO 
interference is not observed in fission yeast, which has only three chromosomes and a relatively large number of COs, reaching up to 44 COs per meiosis (Munz 1994).

How meiotic DSB formation and CO distribution are regulated on a molecular level and how these processes are entangled with the dynamic changes in meiotic chromosome architecture are still poorly understood, but based on the progress made in recent years, C. elegans research will likely contribute significantly to our understanding of these vital processes during meiosis.

\section{Meiotic DSB formation and early DSB processing}

Once Spo11 has catalyzed DSB formation, it remains covalently attached to the $5^{\prime}$ termini of the broken DNA (Keeney et al. 1997; Keeney and Kleckner 1995). To allow HR to occur, this protein-DNA complex must be removed. In yeast, Spo11-bound oligonucleotides are removed by the MRN complex (consisting of Rad50, Xrs2/Nbs1, and the nuclease Mre11) and another associated nuclease known as Sae2 (Keeney and Kleckner 1995; McKee and Kleckner 1997; Milman et al. 2009; Ogawa et al. 1995; Prinz et al. 1997; Fig. 1). Yeast Sae2 deletion mutants allow DSB formation, but are completely defective in Spo11 removal (McKee and Kleckner 1997). This function of Sae2 seems to be conserved in C. elegans, as nematodes lacking the Sae2 homolog com-1 also are able to induce meiotic DSBs; yet, these lesions seem to persist and undergo improper repair, resulting in chromatin aggregates at the diakinesis stage (Penkner et al. 2007). Additionally, com-1 mutants fail to recruit the crucial HR factor RAD-51 to SPO-11induced DSBs, implying a defect in the early processing of SPO-11-bound DSBs. Importantly, these mutants did show many RAD-51 foci upon $\gamma$-irradiation (IR), revealing a specific dependency for COM-1 only at meiotic DSBs (Penkner et al. 2007).

In yeast, the MRN complex is needed for Spo11mediated DSB formation as well as subsequent DSB endprocessing, making it difficult to study these individual (but interdependent) functions of the MRN complex. In yeast, this problem is solved by the identification of separation-offunction alleles of MRN complex components. For example, so-called Mre11-1 and Rad50S mutants allow meiotic DSB formation but are defective in Spo11 removal (McKee and Kleckner 1997; Ogawa et al. 1995). To date, no such mutations have been identified in C. elegans. Nevertheless, both functions of the MRN complex are likely to be conserved: first, germlines that are deficient in mre-11 or rad-50 typically show 12 univalents at diakinesis due to the lack of chiasmata, in line with the role of the MRN complex in meiotic DSB formation (Chin and Villeneuve 2001; Hayashi et al. 2007). Notably, RAD-51 foci are not detected in pachytene nuclei, as expected in the absence of meiotic DSBs. Second, mre-11 mutant nuclei, but not wildtype nuclei, display chromosomal fragmentation upon IR, confirming a defect in DSB end-processing in the absence of the MRN complex (Chin and Villeneuve 2001). Similar to com-1 mutants, both rad-50 and mre-11 mutants can recruit RAD-51 to IR-induced breaks, suggesting that other redundant nucleases exist that can process IR-induced substrates but are unable to act on SPO-11-induced DSBs (Fig. 1). Intriguingly, Hayashi and coworkers discovered that the level of redundancy between these nucleases depends not only on substrate specificity but also on meiotic stage (Hayashi et al. 2007). By carefully analyzing rad-50 mutant germlines, they showed that the dynamics and regulation of RAD-51 loading at IR-induced DSBs changes during meiotic prophase progression. Specifically, these authors discovered a distinct meiotic DSB repair mode, acting from the onset of meiotic prophase until the midpachytene/late pachytene transition, which was characterized by dependence on rad-50 for rapid accumulation of RAD-51 and by the competence for converting IR-induced DSBs into COs (Hayashi et al. 2007). Recently, a study in yeast revealed that Sae2 phosphorylation by cyclin-dependent kinase 1 (Cdk1) is required for Spo11 removal and subsequent DSB processing, providing a mechanism for coordinating DSB repair during meiotic prophase (Manfrini et al. 2010). The critical Cdk-1 phosphorylation motif is evolutionarily conserved, being present in yeast Sae2 and C. elegans COM-1, as well as the human homolog CtIP (Penkner et al. 2007); however, whether such a phosphorylation event also controls early DSB processing during meiotic prophase in these higher eukaryotes still awaits confirmation.

\section{Homology exposure and DNA end resection}

A crucial step in HR is the exposure of sequence information surrounding the DSB in order to search for a homologous template and restore the break. This is achieved by a process called DNA end resection, which involves $5^{\prime}-3^{\prime}$ DNA degradation to create long $3^{\prime}$ single-stranded DNA (ssDNA) tails. These ssDNA tails are initially coated with replication protein A (RPA), which is then replaced by Rad51, the crucial mediator for homologous strand invasion. The observation that DNA end resection can still occur in yeast Sae2 null and Mre11 nuclease-dead mutants (Clerici et al. 2005; Llorente and Symington 2004) has led to a search for redundant activities that can process DSB ends.

One of the strongest candidates for DNA end resection during meiosis is Exo1, as it has $5^{\prime}-3^{\prime}$ exonuclease activity as well as $5^{\prime}$ flap endonuclease activity in vitro, is highly expressed during meiosis, and is known to affect $\mathrm{CO}$ recombination (Lee et al. 1999; Tran et al. 2004). In yeast, Exo1 overexpression suppresses DNA repair defects in mutant cells lacking the MRN complex (Lewis et al. 2002). 
On the other hand, DNA end resection can still occur in Mre11/Exo1 double mutants (Moreau et al. 2001), which is suggestive of further redundancy in this pathway. In 2008, this third pathway was identified and, surprisingly, involved a RecQ helicase (Sgs1) together with an endonuclease (Dna2). In the current model, Sgs1 unwinds both strands at either end of the DSB, and Dna2 (or Exo1) cuts off the exposed $5^{\prime}$ strand, rapidly creating long $3^{\prime}$ ssDNA tails. Several laboratories have established that Sgs1/Dna2 and Exo1 act in parallel pathways to control long-range end resection in mitotic as well as meiotic cells (Fig. 1; Gravel et al. 2008; Huertas 2010; Manfrini et al. 2010; Mimitou and Symington 2008; Zhu et al. 2008). Although Mre11, Rad50, Exo1, Dna2, and RecQ helicases are highly conserved in C. elegans, little is known about end resection in this model organism. For example, the contribution of the MRN complex to DNA end resection is still unclear since the null mutants are defective in meiotic DSB formation and separation-of-function alleles for mre-11 or rad-50 are still lacking. Also, worms lacking only exo-1 show no obvious meiotic defects (B. Lemmens unpublished data), which is in line with the high degree of redundancy and the mild defects in DNA end resection observed in yeast Exo1 single mutants (Manfrini et al. 2010).

While Sgs1 is the sole RecQ helicase in yeast, $C$. elegans has four RecQ helicases and humans have as many as five members of this family. In mammalian cells, EXO1 functions in parallel with the RecQ helicase BLM to promote DNA end resection, DSB signaling, and resistance to DSB-inducing agents (Gravel et al. 2008; Nimonkar et al. 2008). In the worm, deletion of the BLM ortholog him-6 results in radiation sensitivity, increased chromosomal non-disjunction, and shortened lifespan, underscoring the crucial role of this conserved RecQ helicase in genome maintenance (Grabowski et al. 2005; Wicky et al. 2004). Similar to Sgs1 and BLM (Klein and Symington 2009), him-6 has a non-redundant role in one of the final steps of $\mathrm{HR}$, as will be discussed later in this review. Its dual role in the HR process together with the high degree of redundancy in early DSB processing has masked the potential role of him-6 in DNA end resection. Similarly, eukaryotic counterparts of the nuclease Dna2 (including the worm homolog DNA-2) have been implicated in many DNA metabolic processes, complicating interpretation of its DNA repair functions (Budd et al. 2005; Huertas 2010; Kang et al. 2010; Lee et al. 2003). Nevertheless, the C. elegans model system may provide new insights into DNA end resection, as it has been shown to be a useful tool with which to study redundant activities during meiotic DSB repair (Barber et al. 2008; Ward et al. 2010), and unbiased synthetic lethal screens can be employed. Importantly, the genetic interactions between the above-mentioned end resection factors are likely to be conserved, as we recently have observed strong synergystic effects on genome instability upon combined loss of exo-1 and either dna-2 or him-6 (B. Lemmens unpublished data). Although technically challenging, it will be interesting to test whether EXO-1 and HIM-6/DNA-2 are responsible for the residual DNA end resection activity observed in the absence of MRE-11/COM-1. Moreover, the molecular basis for the different DSB repair modes during meiotic prophase progression is still elusive, but could well be regulated via posttranslational modification of the implicated nucleases/helicases (as seen for yeast Sae2 and Exol proteins; Bolderson et al. 2010; Huertas et al. 2008) and/or via their differential expression throughout the worm germline.

Homologous template search and DNA strand invasion

Subsequent to DNA end resection, the $3^{\prime}$ ssDNA tails are protected by RPA, which is subsequently replaced by RAD51 to form a nucleoprotein filament that is able to seek a homologous DNA molecule. In the current model, the invading $3^{\prime}$ end of the broken chromosome binds to the complementary donor strand (either from the sister chromatid or homologous chromosome) and primes DNA synthesis to regenerate the sequence information lost at the break site (Fig. 1). In the case of synthesis-dependent strand annealing (SDSA), the elongated invading strand is then displaced and annealed to the complementary ssDNA tail on the other side of the DSB. The remaining singlestrand gaps are filled and finally the nicks are ligated, resulting in non-CO products only (Fig. 1). During strand invasion, the second DSB end can also be captured by the displacement strand of the donor duplex (D-loop) and can be used to prime another round of DNA synthesis covering the initial DSB. This DSB repair mode ultimately generates a double Holliday Junction (dHJ) intermediate, which can be resolved by endonucleolytic cleavage to form either $\mathrm{CO}$ or non-CO products (Fig. 1).

In order to create the COs needed for successful meiosis, the RAD-51-coated DSB end must invade the homologous chromosome. Therefore, the homologous chromosome must be recognized and positioned close to the broken chromosome. How this is established is still largely unknown, but early homolog recognition and pairing events coincide with marked changes in nuclear morphology. In the nematode, these events involve special regions on each chromosome known as pairing centers (Phillips et al. 2009). During C. elegans meiosis, initial homolog pairing takes place in the "transition zone", when the polarized redistribution of chromosomes gives rise to the characteristically crescent-shaped DNA (Fig. 3). In 2009, two studies provided some molecular insights into this process by linking homology search to cytoskeletal forces and posttranslational modification of the nuclear envelope protein SUN-1 (Penkner 
et al. 2009; Sato et al. 2009). Penkner and coworkers showed that SUN-1 is phosphorylated at its N-terminus and forms rapidly moving aggregates at putative homolog attachment sites in the "transition zone". Similar SUN-1 aggregates were observed after the induction of ectopic DSBs by IR. Importantly, mutation of these N-terminal SUN-1 phosphorylation sites has elicited severe defects in homolog pairing and subsequent $\mathrm{CO}$ formation, ultimately resulting in chromosome univalency at diakinesis. How and whether such protein complexes in the nuclear envelope (together with SC proteins) also affect RAD-51-mediated strand invasion in a more direct fashion is still unclear.

One factor that is known to directly control RAD-51mediated strand invasion in human cells is the well-conserved breast cancer susceptibility gene BRCA2 (Venkitaraman 2001). Human BRCA2 binds RAD51 via a so-called BRC motif, and this interaction is known to stimulate RAD51 multimerization, nucleofilament formation, and HR reactions both in vitro and in vivo (Chen et al. 1998; Davies et al. 2001; Moynahan et al. 2001; Yuan et al. 1999). In order to study the role of BRCA2 during meiotic DSB repair, the Boulton laboratory has investigated the germline functions of the worm homolog BRC-2. BRC-2 is crucial for proper recruitment of RAD-51 to both endogenous and exogenous DSBs in the germline (Martin et al. 2005). In vitro follow-up studies were performed to acquire more mechanistic insights and revealed that recombinant BRC-2, like human BRCA2, stimulates RAD-51-mediated D-loop formation and controls nucleoprotein filament stability (Petalcorin et al. 2007; Petalcorin et al. 2006). In keeping with a role in strand invasion, germlines that are deficient in brc-2 allow RPA recruitment; however, they show abnormal chromosome aggregates due to faulty repair of meiotic DSBs. Interestingly, formation of these chromosomal aggregations depends on LIG-4, a crucial NHEJ factor (Martin et al. 2005). By itself, NHEJ-mediated repair of meiotic breaks can be toxic because it never results in COs, which are required for proper chromosome segregation. Illegitimate HR events can also be detrimental, as they can lead to gross chromosomal rearrangements and tumorigenesis in mammals (Honma et al. 1997; Luo et al. 2000). Therefore, the activities of NHEJ and HR must be tightly controlled during meiotic prophase.

\section{DNA strand invasion and $\mathrm{CO}$ formation}

One of the best-characterized antagonists of HR is the budding yeast helicase Srs2; however, sequence conservation suggests that an obvious homolog is lacking in higher eukaryotes. In 2008, Barber and colleagues reported the identification of a functional Srs2 analog in C. elegans, named rtel-1 (Barber et al. 2008). Although in vitro studies have revealed differences between the biochemical activi- ties of RTEL1 and Srs2, both proteins counteract HR by dismantling DNA strand invasion intermediates. Similar to Srs2 mutants, worms deficient in rtel-1 show hyperrecombination, lethality upon deletion of the RecQ helicase Sgs1/ him-6, and sensitivity to DNA damaging agents. Importantly, human cells depleted of the ortholog RTEL1 exhibit similar hyperrecombination and DNA damage sensitivity phenotypes.

Recently, Youds and coworkers elaborated on the role of RTEL-1 during $C$. elegans meiosis and reported a crucial role for RTEL-1 in CO control (Youds et al. 2010). Specifically, RTEL-1 prevents excess meiotic COs, most likely by promoting meiotic SDSA (Fig. 1). Rtel-1 mutants show an average of two COs per chromosome pair (instead of only one), which totals up to 12 COs per nucleus, implicating a role for RTEL-1 in CO interference. Based on the data from the Meyer lab, this would mean that all meiotic DSBs are converted into COs in the absence of RTEL-1 (Mets and Meyer 2009). These observations also suggest that, in wild-type worms, virtually all meiotic DSBs are repaired via the homologous chromosome, one half through SDSA and the other half via a CO intermediate. Yet, a minor fraction of meiotic DSB may escape repair via the homologous chromosome. In that case, the nearby sister chromatid could be used to faithfully restore the damage, as will be discussed later in this review.

Similar to rtel-1 mutation, loss of the condensin DPY-28 also results in additional COs. However, in $d p y-28$ mutants, this phenomenon is assigned to elevated numbers of meiotic DSBs, rather than altered DSB repair (Mets and Meyer 2009). If RTEL-1 and DPY-28 controlled CO formation via different mechanisms, one would expect to find an additive effect on $\mathrm{CO}$ recombination when these deficiencies are combined. Indeed, rtel-1/dpy-28/+ double mutants have more COs than either single mutant (rtel-1 or $d p y-28 /+)$, resulting in many triple or occasionally even quadruple COs, which implies that RTEL-1 also inhibits $\mathrm{CO}$ formation at these extra-meiotic DSBs. Still, many of the extra DSBs observed in $d p y-28$ single mutants are repaired via a $\mathrm{CO}$ intermediate (despite the presence of RTEL-1), which suggests the existence of a counteracting mechanism that promotes $\mathrm{CO}$ formation. Conceivably, such a mechanism may involve the aforementioned SC components HIM-3 and HTP-1, which are known to restrain intersister HR and therefore promote $\mathrm{CO}$ formation (Couteau et al. 2004; Martinez-Perez and Villeneuve 2005).

Recently, two additional factors, $r f s-1$ and helq- 1 , have been implicated in the post-invasion steps of HR and, as predicted, interact genetically with rtel-1 (Ward et al. 2010). The RAD-51 paralog RFS-1 and the helicase HELQ-1 promote postsynaptic RAD-51 filament disassembly during C. elegans meiosis. Here again, redundant mechanisms have evolved to ensure proper meiotic DSB repair, as only 
the combined deficiency of both $r f_{s}-1$ and helq- 1 results in the persistence of RAD-51 foci, severe chromosomal aberrations, and, consequently, unviable progeny. Based on in vitro studies, RFS-1 and HELQ-1 both bind RAD-51 and work in complementary but mechanistically different pathways to promote RAD-51 removal from dsDNA. Interestingly, the phenotypes of the helq-1/rfs-1 double mutants are very similar to those observed in C. elegans rad-54 mutants (Mets and Meyer 2009). In Saccharomyces cerevisiae, Rad54 mutants are defective in HR and also exhibit retarded removal of Rad51 (Shinohara et al. 2000; Solinger and Heyer 2001). Yeast Rad54 is a motor protein that translocates along dsDNA and performs several important functions in HR, including the stimulation of Rad51-mediated strand exchange, extension of heteroduplexes, and chromatin remodeling (Mazin et al. 2010). Rad54 may well have identical roles in C. elegans because, in rad-54 mutant germlines, virtually all SPO-11-induced DSBs persist and retain RAD-51 proteins, causing these worms to be completely infertile (Mets and Meyer 2009).

As portrayed above, homology search and subsequent strand invasion steps are intriguing but complex processes and involve many factors that often have multiple roles in genome maintenance. Moreover, several backup mechanisms appear to exist to guarantee faithful HR-mediated repair of meiotic DSBs. Many of the aforementioned meiotic DSB repair factors have only recently been discovered or characterized in detail, and many questions follow from these studies, such as how do all these seemingly redundant factors interact genetically, how is their activity regulated, and what determines repair template choice?
Holliday junction resolution

One of the final intermediates in HR is the so-called dHJ intermediate, which consists of two complex four-way DNA joints known as Holliday junctions (HJs); (Figs. 1 and 4). These HJs tie the chromosomes to each other and must eventually be resolved to complete meiosis (and other forms of HR-mediated DSB repair). In 1991, two research groups jointly discovered an enzyme in Escherichia coli capable of resolving these HJs (Connolly et al. 1991; Sharples and Lloyd 1991). This discovery evoked a challenging search for eukaryotic equivalents of this bacterial HJ resolvase - a mission that was surprisingly difficult and took almost 20 years to accomplish (see West 2009 for an excellent historical overview). The bacterial RuvC enzyme is able to symmetrically cleave HJs in vitro and generates products that can be religated without further processing. For decades, this activity has served as a textbook model for meiotic $\mathrm{dHJ}$ resolution because such an activity could create non-COs (when the same pair of strands are cleaved in both junctions) as well as obligate COs (when different strand pairs are cleaved at each intersection) (Fig. 4; Szostak et al. 1983). This model predicts that both $\mathrm{COs}$ and non-COs derive from $\mathrm{dHJ}$ intermediates. Classical HJ resolvases (like RuvC) cleave either pair of strands with equal probability, which is consistent with observations in S. cerevisiae and C. elegans, in which half of the meiotic DSBs are converted into COs. However, several observations challenge the idea that the orientation of $\mathrm{HJ}$ resolution accounts for the relative frequencies of COs and non-COs. For example, several mutations have been found in yeast that reduce $\mathrm{CO}$

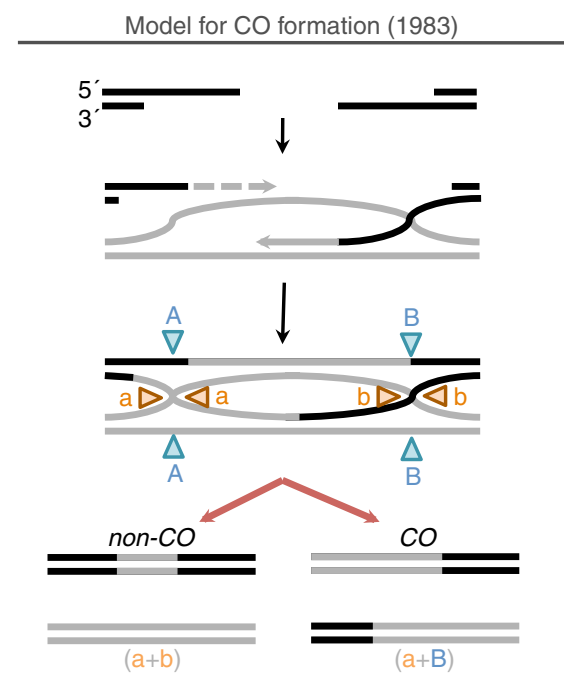

Fig. 4 Different models for CO formation. Schematic representation of the DSB repair model as postulated by Szostak et al. in 1983, in which $\mathrm{CO} /$ non-CO outcome is determined by the orientation of $\mathrm{dHJ}$

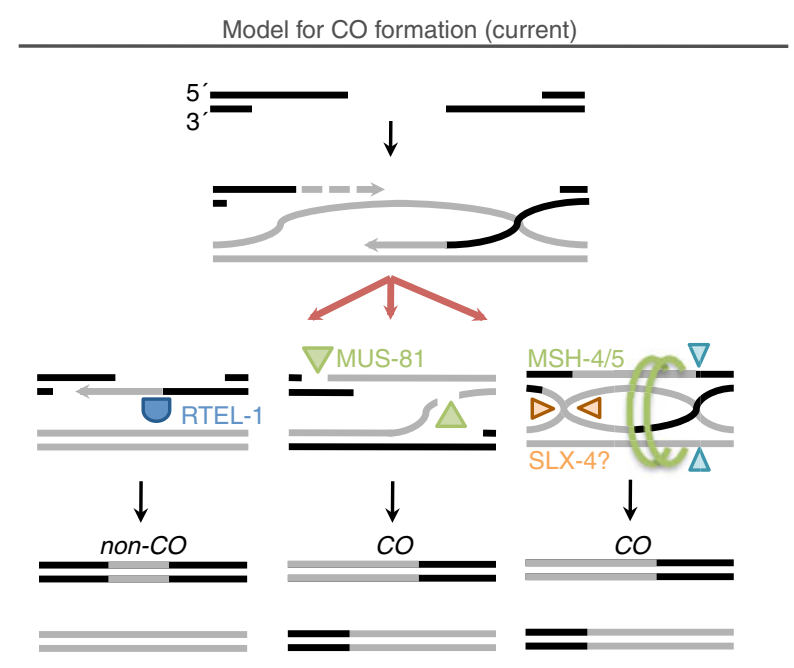

resolution (left), and the current model, in which $\mathrm{CO} /$ non-CO designation occurs before $\mathrm{dHJ}$ formation (right) 


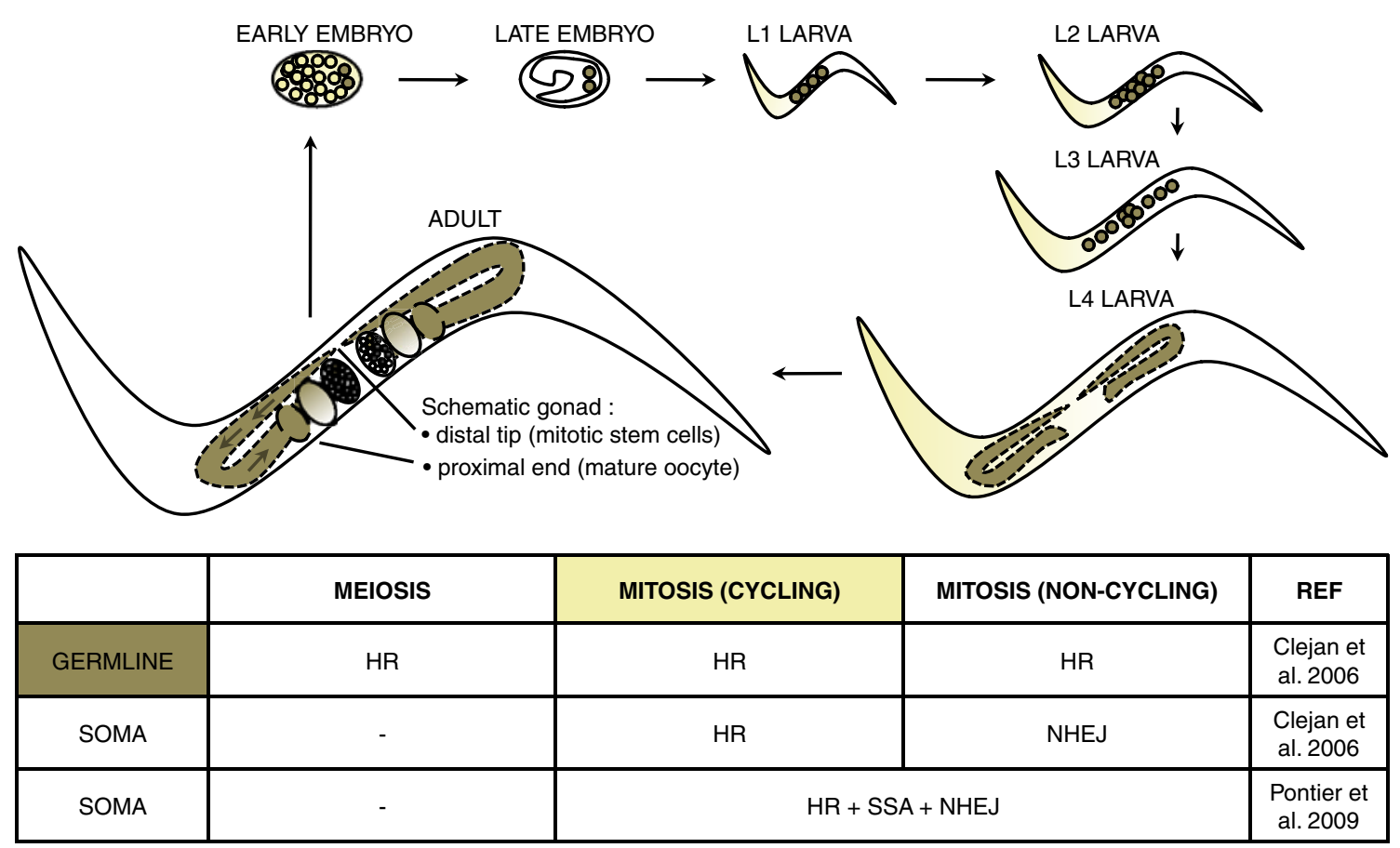

Fig. 5 Overview of the major DSB repair pathways that are active during C. elegans development. See text for details

recombination without affecting either the number of nonCOs or the formation of DSBs (Whitby 2005). Moreover, in worms defective in SDSA, all meiotic DSBs appear to be converted into COs (Youds et al. 2010). This indicates that COs and non-COs derive from independent pathways of DSB repair. In fact, current models suggest that dHJs are resolved exclusively as COs, although the underlying mechanism is still unknown (Fig. 4).

An important set of proteins involved in HJ resolution are the so-called ZMM (Zip1, Zip2, Zip3, Msh4, Msh5 and Mer3) proteins, among which ZHP-3, MSH-4, and MSH-5 are the best-studied members in C. elegans (Bhalla et al. 2008; Colaiacovo et al. 2003; Winand et al. 1998). In yeast, ZMM proteins appear to stabilize single-end invasion intermediates and promote $\mathrm{dHJ}$ formation and subsequently ensure that $\mathrm{HJ}$ resolution occurs with the appropriate bias to generate COs (Borner et al. 2004; Fung et al. 2004). Also, ZMM proteins localize to DSBs destined to be converted into $\mathrm{COs}$, specifically those that are subject to $\mathrm{CO}$ interference (Lynn et al. 2007). Accordingly, transgenic worms carrying a ZHP-3::GFP protein-fusion construct show six GFP foci in diplotene nuclei, one focus per chromosome pair (Bhalla et al. 2008). Moreover, worms carrying mutations in ZMM genes (e.g., $m s h-4$ or $m s h-5$ null mutants) are unable to generate the six obligate COs, resulting in 12 univalents at diakinesis (Kelly et al. 2000; Zalevsky et al. 1999). This strict requirement of ZMM proteins for proper meiotic $\mathrm{CO}$ formation is also seen in mammals; for instance $\mathrm{Msh}^{-/-}$and $\mathrm{Msh}^{-/-}$mice are infertile and exhibit defects in chromosome pairing during meiosis I (de Vries et al. 1999; Edelmann et al. 1999; Kneitz et al. 2000). While the exact role of the ZMM proteins remains to be elucidated, human MSH4-MSH5 heterodimers are thought to recognize HJs and encircle the adjacent duplex DNA, where they could serve to stabilize the HJ intermediate and/or recruit factors capable of resolving HJs (Snowden et al. 2004; Fig. 4).

In 2008, Ip and collaborators were the first to identify nucleases from budding yeast and human cells that promote $\mathrm{HJ}$ resolution in vitro, in a manner reminiscent of the bacterial HJ resolvase RuvC (Ip et al. 2008). Via extensive fractionation and mass spectrometry analysis of nuclear extracts derived from 200 liters of Hela cells, they discovered the human HJ resolvase GEN1. A parallel screen using a yeast gene fusion library yielded a similar Rad2/ XPG nuclease called Yen1 (Ip et al. 2008).

A mutant of the worm ortholog, gen-1, has recently been identified in the Gartner lab, using an unbiased forward genetic screen for DNA damage-induced cell cycle arrest (Bailly et al. 2010). Its function as an HJ resolvase appears to be conserved, since GEN-1 shows HJ resolution activity in vitro, and worms lacking gen-1 are hypersensitive to DSB-inducing agents and show persistent RAD-51 foci after IR treatment, suggestive of inefficient DSB repair. However, gen-1 null mutants are fertile and show no change in $\mathrm{CO}$ recombination which suggests that gen-1 functions primarily as a checkpoint gene in $C$. elegans, or that other factors exist that work redundantly to gen- 1 at the level of HJ resolution (Bailly et al. 2010). 
In 2009, four studies reported the identification of a novel protein complex able to process HJs analogous to RuvC/GEN1. This complex consisted of the scaffold protein SLX4 and the endonuclease SLX1 (Andersen et al. 2009; Fekairi et al. 2009; Munoz et al. 2009; Svendsen et al. 2009). Human SLX4 is thought to act as a coordinating platform for multiple endonucleases to control cleavage of various damaged or branched substrates, including HJs (Fekairi et al. 2009; Svendsen et al. 2009). In vitro studies using SLX1 immunoprecipitates from human cells or SLX4/SLX1 complexes purified from $E$. coli suggest that the interaction between SLX4 and SLX1 is required for symmetric $\mathrm{HJ}$ resolution. Previous work in Drosophila had already identified a protein named MUS312, which was similar to SLX4 (and interacted with the fly XPF homolog MEI-9) and was needed for proper meiotic recombination, revealing the impact of SLX4 deficiency in a developing animal. Recently, such a role was substantiated by Saito and colleagues, who showed that the worm homolog SLX-4 was required for processing HR intermediates in both mitotic and meiotic nuclei in the $C$. elegans germline (Saito et al. 2009). Slx-4 mutant animals show a reduction in $\mathrm{CO}$ recombination frequencies and increased levels of strand invasion intermediates (RAD-51 foci), accompanied by elevated germ cell apoptosis, unstable bivalent attachments, and chromosome nondisjunction. Still, homozygous slx-4 mutants are able to produce viable offspring and frequently show six bivalents at the diakinesis stage, indicating that redundant activities exist that ensure CO formation in the absence of SLX-4. In accordance with the proposed "scaffold function" of its human counterpart, C. elegans SLX-4 also interacts with multiple structure-specific endonucleases, including SLX-1 and XPF-1 (Saito et al. 2009). At present, one deletion allele of $s l x-1$ is available, likely resulting in a truncated SLX-1 protein that still contains its highly conserved nuclease domain. Unfortunately, this allele is reported not to be a strong loss-of-function allele, hampering its use for in vivo analysis of SLX-1 function (Saito et al. 2009). In addition, the exact role of the interaction between SLX-4 and XPF-1 in meiotic $\mathrm{CO}$ formation is still unclear. Although xpf-1-deficient worms show meiotic defects similar to those observed in the absence of slx-4 (including a reduction in $\mathrm{CO}$ frequency and elevated chromosomal non-disjunction), the phenotypes in $x p f-1$ single mutants are clearly milder than those observed in slx-4 single mutants (Saito et al. 2009).

\section{Holliday junction processing}

In addition to these $\mathrm{HJ}$ resolvases, other mechanisms have evolved to ensure CO formation. In Schizosaccharomyces pombe, $\mathrm{CO}$ formation mainly depends on another highly conserved endonuclease called Mus81. Mus81 mutants in fission yeast produce virtually no viable spores $(<1 \%$ survival) due to defects in chromosome segregation during meiosis I (Boddy et al. 2000; Osman et al. 2000). In contrast, Mus81 mutants in budding yeast still produce $60 \%$ viable spores. Higher organisms seem to depend even less on Mus81 to repair meiotic DSBs, as C. elegans mus- 81 mutants produce up to $80 \%$ viable progeny and Mus $81^{-/-}$mice are fertile and show only minor meiotic defects (Dendouga et al. 2005; McPherson et al. 2004; Saito et al. 2009). Recent studies have revealed overlapping roles for GEN1/Yen1 and Mus81 in HJ resolution at collapsed replication forks, as well as at meiotic DSBs (Lorenz et al. 2010; Tay and Wu 2010). The extreme dependence on Mus81 to process meiotic HJs, as observed in $S$. pombe, may be explained by the fact that this yeast species appears to lack an obvious Yen1 ortholog. In addition, fission yeast seems to be deprived of MSH4MSH5 orthologs, which is also consistent with the observed lack of $\mathrm{CO}$ interference.

Several studies on Mus81 function indicate that this nuclease may act early during DSB repair, generating COs by processing non-dHJ intermediates (Heyer et al. 2003; Osman et al. 2003). In that vein, Mus81 in budding yeast has been shown to work together with the Bloom syndrome helicase Sgs1 to resolve aberrant joint molecules that may arise during meiotic recombination (Jessop and Lichten 2008; Oh et al. 2008). Such a function of MUS-81 could explain the fact that $C$. elegans mus-81/rtel-1 double mutants are completely infertile and exhibit many persistent RAD-51 foci in pachytene nuclei because, in the absence of RTEL-1, toxic strand invasion intermediates may arise that require MUS-81 function for their resolution. In keeping with the cooperative functions of Mus81 and Sgs1 in yeast, him-6/ rtel-1 double mutant worms also show an elevated level of meiotic RAD-51 foci and increased embryonic lethality compared with either single mutant (Barber et al. 2008). Although wild-type worms appear to depend exclusively on ZMM-mediated $\mathrm{HJ}$ resolution for $\mathrm{CO}$ formation, a recent study revealed that, in absence of rtel-1, ZMM-independent CO routes do exist in C. elegans (Youds et al. 2010). Similar to yeast, this ZMM-independent class of COs required mus-81 (Hollingsworth and Brill 2004; Youds et al. 2010). Together, these data argue that MUS-81 does not function as a central HJ resolvase in $C$. elegans; however, it likely serves as an important backup to ensure proper HJ resolution.

\section{Holliday junction dissolution}

To complicate matters even further, nature has come up with another solution to resolve $\mathrm{dHJ}_{\mathrm{S}}$, i.e., a process termed "dissolution" that does not require structure-specific nucleases. In dissolution, dHJs are untangled via ssDNA decatenation by a helicase-topoisomerase complex. In 
yeast, dissolution is performed by Sgs1, Top3, Rmi1, and RPA, and exclusively generates non-CO products (Chen and Brill 2007; Plank et al. 2006; Wu and Hickson 2003). The Sgs1 helicase has multiple redundant roles during HR, which are reflected by its many synthetic lethal interactors, including Dna2, Mus81, Slx4, and Srs2 (Pan et al. 2006). However, the Sgs1 helicase has non-redundant activities as well, illustrated by the fact that Sgs1 mutation results in reduced spore viability. Similarly, C. elegans single mutants lacking only the Sgs1 ortholog him-6 show reduced progeny survival and elevated levels of chromosomal nondisjunction. In yeast, the predominant non-redundant meiotic function of this RecQ helicase seems to involve a non-CO pathway, as Sgs1 single mutants display an increase in CO frequency (Rockmill et al. 2003). On the contrary, worms deficient in him-6 mainly exhibit phenotypes that suggest a key role in a CO pathway: him- 6 single mutants exhibit up to $50 \%$ reduction in $\mathrm{CO}$ recombination and severe defects in chiasmata formation (Wicky et al. 2004). Moreover, when all DSBs are skewed into CO pathways (e.g., by blocking the principal non-CO pathway in C. elegans via rtel-1 mutation), meiotic nuclei seem to depend even more on HIM-6 for proper DSB repair (Barber et al. 2008). This suggests that, either the main function of this RecQ helicase has changed over the course of evolution, or the dependency on its specific functions has diverged between the different species.

In theory, the relative roles of the worm orthologs HIM-6 and TOP-3 during meiotic HJ resolution and/or dissolution could be assessed by epistasis analysis. Unfortunately, this is not feasible in the worm because him-6/top-3 double mutants suffer from mitotic catastrophe, resulting in a massive increase in DSBs already in the mitotic zone of the germline (Wicky et al. 2004).

A long-standing question has concerned the mechanisms by which $\mathrm{dHJ}$ intermediates are resolved, and as described above, recent studies have led to the identification of many crucial factors involved (Figs. 1 and 4). Still, exciting times await us, since now, these pieces of the puzzle need to be placed correctly in the redundant networks that ensure proper HJ resolution. As a proven genetic model for metazoan meiosis, C. elegans will likely contribute in shaping this research field, e.g., by revealing the in vivo consequences of $\mathrm{HJ}$ resolution defects in complex genetic backgrounds.

Meiotic DSB repair via the sister chromatid

One of the interesting questions in the meiosis field concerns the choice of the two possible repair templates of programmed DSBs, i.e., the sister chromatid or the homologous chromosome. Half of the DSBs are converted into $\mathrm{COs}$ and therefore use the homologous chromosome for repair. Repair of the other DSBs, via non-CO sub-routes of HR, does not necessarily involve the homologous chromosome: SDSA is the major non-CO repair route in the $C$. elegans germline, which could well use any homologous template (the sister or the homolog). As discussed earlier, most data thus far point towards the exclusive use of the homologous chromosome; however, inter-sister HR can also contribute to meiotic DSB repair. In 2008, Adamo and colleagues described the function of BRC-1, the homolog of the well-studied HR factor and breast cancer tumor suppressor BRCA1, and showed that it acts (almost) exclusively in inter-sister HR in the worm germline (Adamo et al. 2008). Null mutants of brc-1 are viable, fertile, and exhibit the wild-type compliment of six bivalents in most diakinetic nuclei, indicative of successful CO recombination. However, brc-1 mutants show persistent SPO-11-dependent RAD-51 foci at the late pachytene stage and a mild level of chromosome non-disjunction, revealing its role in meiotic DSB repair. Furthermore, brc-1 mutant germlines are hypersensitive to DSB-inducing agents such as camptothecin and IR (Ward et al. 2007). When DSB repair via the homologous chromosome is not possible (e.g., in the absence of SC genes), loss of brc-1 leads to severe chromosome fragmentation, suggesting that $b r c-1$ is crucial for meiotic DSB repair through inter-sister HR (Adamo et al. 2008). Notably, the vertebrate orthologs of brc-1 and com-1 (BRCA1 and CtIP, respectively) modulate DSB repair pathway choice during the different mitotic cell cycle phases (Yun and Hiom 2009). How exactly brc-1 controls DSB repair during meiosis is still unclear, but it likely functions in concert with one of its many binding partners, as several recent proteomic and genetic studies have revealed the presence of various distinct BRCA1 complexes in vivo, each of which governs a specific cellular response to DNA damage (reviewed in Huen et al. 2009).

Recently, two other players, SMC-5 and SMC-6, have been described to have an important role in meiotic intersister HR (Bickel et al. 2010). The meiotic phenotypes of $s m c-5 / s m c-6$ mutants are very similar to brc-1 mutants, including normal chiasmata formation, IR hypersensitivity, and severe chromosomal fragmentation upon loss of interhomolog HR. Then again, smc-5/smc-6 single mutants already show a high degree of chromosome fragmentation at the diakinesis stage, a phenotype rarely seen in brc-1deficient germlines. This latter observation implies that a significant number of meiotic DSBs still need to be repaired via inter-sister HR to safeguard germ cell genomic integrity and that this process may not be completely disrupted in brc-1 mutants (Bickel et al. 2010).

Signaling events in the germline

As portrayed above, DSB repair during meiosis requires many factors, which all need to be active only at a specific 
stage, location, and/or designated substrate. Importantly, HR (the principal repair route in the germline) is a dynamic process that involves both factors that favor recombination reactions and factors that counteract these intermediates. Tight regulation of the repair proteins involved is necessary to safeguard genomic stability and ensure the formation of the obligate COs. Posttranslational modifications, such as phosphorylation, ubiquitination, and SUMOylation are rapid, dynamic, and reversible means of regulation that could control many of the steps in meiotic prophase progression. Indeed, several highly conserved kinases have been shown to be crucial for proper DSB repair during meiosis.

Phosphorylation events in the germline

An important set of kinases implicated in the DSB response belong to the phosphatidylinositol-3 kinase related kinase (PIKK) family, among which ATM (atm-1) and ATR (atl-1) are the best-characterized in C. elegans. Both ATM and ATR are believed to be the primary sensors of DNA damage and phosphorylate numerous substrates involved in cell cycle checkpoint, apoptosis, and DNA repair (Matsuoka et al. 2007; Smolka et al. 2007). Although ATR and ATM share many of their downstream substrates, they primarily respond to different types of lesions and accordingly show different modes of activation and recruitment (Garcia-Muse and Boulton 2005; Hurley and Bunz 2007). In human mitotic cells, ATM mainly responds to IR-induced DSBs, whereas ATR primarily acts at lesions arising from replication fork stalling and UV damage (Cimprich and Cortez 2008; Czornak et al. 2008). A recent study that exploited the C. elegans germline to investigate the activation and recruitment of PIKKs after different types of DNA damage revealed an unexpected role for the RecQ helicase WRN-1 in the recruitment of ATM-1 to IR-induced damage (Lee et al. 2010). Although WRN helicases are well-known for their roles in replication, DNA repair, and telomere maintenance, such an upstream role in DSB recognition and checkpoint activation had not been previously anticipated (Rossi et al. 2010). Whether the WRN helicase has a role in ATM activation also in human cells still awaits confirmation.

In budding yeast, the ATM/ATR homolog Mec1 is required for proper meiotic progression, as Mec1 mutants show a reduction in meiotic recombination, loss of interhomolog bias, and defective CO control (Carballo and Cha 2007). PIKKs also seem to affect meiotic CO control in higher organisms; for example, Drosophila mutants lacking the ATR homolog Mei-41 and $\mathrm{Atm}^{-/-}$mice both show altered CO distributions (Barchi et al. 2008; Gatti et al. 1980). In C. elegans, atl-1 and atm-1 single mutants display the normal six bivalents during diakinesis, indicating that ATR and ATM are not absolutely required for $\mathrm{CO}$ formation. However, these kinases could still play a role in $\mathrm{CO}$ interference. Interestingly, the protein sequence of RTEL-1 contains a putative ATM/ATR phosphorylation motif that is well-conserved among flies, mice, and humans. Whether and how the PIKK kinases affect $\mathrm{CO}$ distribution in the worm still remains to be addressed.

With regard to possible downstream targets of ATM signaling, it should be noted that it is an outstanding question whether the H2Ax signaling cascade that amplifies the DNA damage response in mammals is "functionally" conserved in C. elegans. The genome of the worm does not encode an $\mathrm{H} 2 \mathrm{Ax}$ ortholog nor is there an obvious motif present in, e.g., H2A that could serve as an ATM-dependent DSB chromatin mark. While other components involved in the more downstream part of this signaling cascade also seem to be missing (e.g., MDC1 and RNF8), some are likely conserved, as $h s r-9$ encodes a protein that is closely related to 53BP1.

The polo-like kinase (PLK) family is another class of kinases that is important for faithful chromosome segregation and DSB response. For instance, Cdc5 (the sole PLK in yeast) promotes $\mathrm{HJ}$ resolution and proper chromosome separation during meiosis (Clyne et al. 2003; Sourirajan and Lichten 2008). Humans have four PLKs and while their role in mitosis is widely studied, their function during meiosis is largely unknown (Archambault and Glover 2009). The C. elegans genome contains three PLK paralogs, and mutations in plk-1 and plk-2 have recently been shown to display strong meiotic defects (Chase et al. 2000a, b; M. Zetka, personal communication). An additional kinase shown to control meiotic progression and affect genomic stability during worm gametogenesis is CHK-2; however, whether this protein has a direct role in DSB repair is unknown (MacQueen and Villeneuve 2001).

Ubiquitination events in the germline

In addition to these phosphorylation events, other modes of posttranslational modification (such as ubiquitination and SUMOylation) are likely to control DSB repair, as they do in other model organisms (Boulton 2009). For example, mammalian BRCA1 and its related binding partner BARD1 form a heterodimeric complex that acts as an ubiquitin E3 ligase (Hashizume et al. 2001). Since the enzymatic activity of the BRCA1/BARD1 complex is conserved over a broad phylogenetic range, it is thought to be critical for the central functions of BRCA1. However, Reid and coworkers recently revealed that key aspects of BRCA1 function in genome maintenance in mammalian ES cells, including its role in HR-mediated DSB repair, do not depend on the E3 ligase activity of BRCA1 (Reid et al. 2008). The C. elegans BRCA1 and BARD1 homologs (BRC-1 and BRD-1, respectively) have been shown to form an active ubiquitin 
ligase in vitro (Boulton et al. 2004; Polanowska et al. 2006). Notably, this BRC-1/BRD-1 complex is activated on chromatin in vivo after IR damage and is responsible for many ubiquitination events at IR-induced lesions in the mitotic zone of the germline (Polanowska et al. 2006). Unfortunately, the identity of these IR-dependent BRC-1 substrates is still unknown. Moreover, the significance of these BRC-1-dependent ubiquitination events for genomic stability still needs to be addressed.

\section{DSB repair and the mitotic cell cycle}

\section{Mitotic DSB repair and development}

As described in the previous sections, HR pathways ensure genomic stability in meiotic cells by faithfully repairing all the programmed DSBs introduced by SPO-11. Maintaining genomic integrity in gametes is crucial to create viable offspring and thereby promotes species survival. However, the challenge does not end here, especially for multicellular organisms like $C$. elegans and humans, which must generate complex somatic tissues to support their germline. When two gametes merge to form a zygote, this single cell has to divide numerous times to form a healthy and fertile multicellular organism that is able to cope with the countless challenges it will encounter before it can complete its life cycle. During animal development and in tissues that are continuously replenished in adults (e.g., the human intestine and the hematopoietic system), many cells are actively cycling in order to create new diploid daughter cells.

Whereas DSBs can occur at any stage of the cell cycle, proper repair templates are not always available. During and after DNA replication, sister chromatids are held in close proximity to each other by cohesins, providing a convenient template for homology-based DSB repair (Nasmyth and Haering 2009). Accordingly, HR is mainly active in S/G2 (Beucher et al. 2009; Delacote and Lopez 2008). In contrast, NHEJ does not require a homologous template and has been shown to be active during all stages of the cell cycle (Beucher et al. 2009). Because HR is principally error-free and NHEJ is error-prone, cell cycle stage is an important determinant for DSB repair fidelity. In addition, cell fate is an important determinant for the consequences of unfaithful DSB repair: stem cells producing the germline harbor the genetic material that is passed on to next generation and their genomic integrity is thus crucial to the identity and survival of the species. On the contrary, cells that form or replenish the soma are needed for the survival and fitness of the individual. For that reason, genomic stability in somatic cells determines the health of the individual and, with that, its ability to reproduce. Especially in long-lived animals, somatic genome instability can lead to the accumulation of genetic insults that may promote aberrant cellular behavior, ultimately leading to lethal diseases such as cancer. Even in short-lived animals that do not develop tumors, such as C. elegans, both cell cycle stage and cell fate have been demonstrated to greatly affect DSB repair.

DSB repair in the mitotic germline

In $C$. elegans, the germline is set apart from the soma already early during embryogenesis: during the first embryonic divisions only a few blastomeres (belonging to the so-called P-lineage) acquire germline potential, culminating in a single germline founder cell named P4 (Sulston et al. 1983). This P4 cell does not contribute to the soma, but divides to give rise to two primordial germ cells (named Z2 and Z3), which eventually will spawn all germline nuclei/cells (Fig. 2). Germline cells are the only cells in the adult animal that are mitotically proliferating; all other cells can be considered somatic (predominantly terminally differentiated) and are born through an invariant lineage mostly during $C$. elegans embryonic development, which for convenience can be divided into two distinct phases: an "early stage" that is marked by rapid mitotic divisions, resulting in approximately 550 cells in less than $6 \mathrm{~h}$; and a "late stage" of $8 \mathrm{~h}$ that is virtually devoid of cell divisions (Fig. 5). Interestingly, in late-stage embryos, the mitotic primordial germ cells $(\mathrm{Z} 2 / \mathrm{Z} 3)$ arrest in $\mathrm{G} 2$, whereas the surrounding somatic cells temporarily halt in G1 (Clejan et al. 2006). Similar results have been observed in dauer larvae, which may have to store their non-dividing germline stem cells for weeks. This specific feature of germ cells could well be evolved to facilitate error-free HR in order to protect the genetic information passed on to future generations. Indeed, germ cells seem to depend exclusively on HR for IR resistance during all stages of development (Fig. 5; Clejan et al. 2006). In contrast, somatic cells have been shown to depend on HR as well as error-prone means of DSB repair to maintain genome stability (Fig. 5; Clejan et al. 2006; Pontier and Tijsterman 2009).

Many of the factors shown to be involved in meiotic HR are also contributing to mitotic HR. Accordingly, several mutants that exhibit defects in HR during the meiotic stages of the germline also display increased genomic instability in mitotic cells. As an example, previously discussed him-6 and xpf-1 mutants show elevated levels of RAD-51 foci also in the mitotic zone of the adult germline, suggesting that these HR factors act both on programmed meiotic DSBs and on spontaneous DSBs that arise in mitotic cells (Saito et al. 2009; Wicky et al. 2004). Another example: worms that lack factors involved in meiotic $\mathrm{HJ}$ resolution (e.g., SLX-4 or MUS-81) show elevated RAD-51 foci in 
the mitotic region of the germline (Saito et al. 2009). On the other hand, some HR steps seem to be differentially regulated at mitotic DSBs and meiotic DSBs. For instance, rad-50 and com- 1 mutants show a number of strong RAD51 foci in the mitotic zone but are completely incapable of loading RAD-51 at SPO-11-bound DSBs during meiosis (Hayashi et al. 2007; Penkner et al. 2007). While this could reflect the different natures of meiotic and mitotic DSBs, the distinct kinetics of RAD-51 loading at IR-induced DSBs suggests that DNA end resection is differently regulated in mitotic and meiotic cells (Hayashi et al. 2007). Downstream HR processes also seem to be differentially regulated, as helq-1/rfs-1 double mutants are deficient in RAD-51 removal from meiotic DSBs but show no persistent RAD-51 foci in the mitotic compartment of the germline (Ward et al. 2010).

Apart from different genetic requirements for the repair of DSBs in mitotic versus meiotic cells, the intermediate DNA substrates onto which the various DSB repair proteins act may be fundamentally different. Although Bzymek and colleagues very recently reported DSB repair intermediates in mitotic yeast cells whose strand composition and size were identical to the dHJs that arise during meiosis, they also observed some fundamental differences (Bzymek et al. 2010): the joint molecules that arise during mitotic DSB repair preferentially occur between sister chromatids, whereas meiotic dHJs principally occur between homologous chromosomes. Moreover, $\mathrm{dHJ}$ intermediates seem to represent a minor pathway of DSB repair in mitotic cells, being detected at approximately tenfold lower levels (per DSB) than during meiotic recombination.

\section{DSB repair in somatic cells}

Somatic cells do not depend solely on HR to repair a DSB, but instead use both high-fidelity and error-prone DSB repair pathways. An important and well-studied error-prone DSB repair pathway is NHEJ. In human cells, NHEJ requires, at the very least, the $\mathrm{Ku} 70 / \mathrm{Ku} 80$ heterodimer complex for DSB recognition and the XRCC4-Ligase IV complex in order to seal the break. In addition, efficient NHEJ requires the protein kinase DNA-PKcs and DSB end-processing enzymes, such as Artemis (Burma et al. 2006; Fig. 1). Both the Ku proteins (CKU-70/CKU-80) and Ligase IV (LIG-4) are conserved in C. elegans and have been shown to be crucial for resistance to DSB-inducing agents during certain developmental stages (Clejan et al. 2006). Mammalian DNA-PKcs is able to bridge DSB ends in vitro (DeFazio et al. 2002) and is shown to be critical for NHEJ activity in vivo (Kurimasa et al. 1999). Remarkably, based on sequence identity, nematodes (and all yeast species) seem to lack an obvious DNA-PKcs homolog. Artemis is an SNM1-like exonuclease that, upon complex formation with DNA-PKcs, acquires endonucleolytic activity capable of processing complex DSBs, including the DSBs that occur in lymphocytes during $\mathrm{V}(\mathrm{D}) \mathrm{J}$ recombination (Pannicke et al. 2004). The C. elegans genome contains only a single gene that belongs to the SNM1 family: mrt-1. Surprisingly, worms lacking MRT-1 do not display the IRinduced somatic defects normally seen in strains deficient for any of the core NHEJ subunits lig-4, cku-70, or cku-80 (Meier et al. 2009). Instead, mrt-1 mutation results in hypersensitivity to DNA crosslinking agents, a phenotype shared with human SNM1 and many other HR factors (Meier et al. 2009). Together, these observations could suggest that the worm can do with a minimal set of NHEJ factors consisting only of three core proteins (CKU-70, CKU-80, and LIG-4); however, a saturated and unbiased screen for factors specifically affecting in vivo NHEJ activity has yet to be performed.

In 2006, Clejan and coworkers investigated the relative contribution of HR and NHEJ in somatic C. elegans cells by looking at developmental abnormalities induced by IR damage (Clejan et al. 2006; Fig. 2). Using several IR assays, they revealed that such cells employ both HR and NHEJ to repair exogenous DSBs (Fig. 5); however, these repair pathways were employed in different cellular contexts. When DSBs were introduced in highly proliferative somatic cells by irradiating "early stage" embryos, embryonic survival depended exclusively on HR factors, including the MRN complex components rad-50 and mre-11, and downstream effectors $\mathrm{rad}-51$ and $\mathrm{rad}-54$. The absence of NHEJ failed to enhance their hypersensitivity to IR (in both HR proficient and HR-depleted backgrounds), suggesting a nonredundant role for HR in the repair of IR-induced damage in the early embryo (Fig. 5). In contrast, when DSBs were introduced in non-cycling cells by irradiating "late stage" embryos, DSB repair depended primarily on NHEJ rather than HR (Fig. 5). Therefore, cell cycle progression clearly affects DSB repair pathway "choice". Although irradiated late-stage embryos do hatch, they show a variety of severe post-embryonic defects, especially in tissues that require cell proliferation during larval development (Fig. 5). Similar to the situation during early embryogenesis, faulty DSB repair followed by cell cycle progression can result in major developmental defects.

IR is often used to study DSB repair because it is an efficient way of inflicting DSBs. However, IR actually induces many other types of DNA damage as well, including SSLs (Cadet et al. 2004). Our laboratory recently developed a transgenic reporter system that specifically detects DSB repair in the somatic cells of a developing worm (Pontier and Tijsterman 2009). This reporter system is based on inducible expression of the rare-cutting endonuclease I-SceI, which generates a single DSB specifically at the integrated reporter locus. Various well- 
known DSB repair factors (those needed for HR, NHEJ, or SSA) were probed for their relative contributions to DSB repair in somatic cells leading to the notion of a dynamic and robust network of DSB repair pathways that governs genome integrity during $C$. elegans development. For example, loss of HR (via either rad-51 RNAi or brc-1 mutation) resulted in a strong increase in SSA activity. Similarly, when crucial NHEJ factors were mutated, other DSB repair pathways (including SSA and MMEJ) compensated for the loss. In addition, Pontier revealed that $C$. elegans XPF-1 (in addition to its function in HR in the germline) has a conserved role in SSA in somatic cells, matching the SSA defects observed in Rad1/Xpf-deficient mitotic yeast cells (Klein 1988; Pontier and Tijsterman 2009; Prado and Aguilera 1995). Although this I-SceIbased reporter system revealed (error-prone) repair events in many different tissues, the exact identity of the cells involved and their proliferative states at the moment of DSB induction has yet to be determined (Figs. 2 and 5).

\section{Concluding remarks}

The toxicity of DSBs, which threatens all living organisms, has led to the evolution of various DSB repair pathways, including NHEJ, HR, MMEJ, and SSA. The fact that cells do not rely on a single DSB repair route, but instead have developed a complex network of redundant DSB repair mechanisms, underscores the risk of faulty DSB repair. Moreover, there seems to be immense evolutionary pressure on proper DSB repair, as many DSB repair factors are wellconserved from yeast to mammals. Paradoxically, the same evolutionary pressure has led to the existence of highly regulated developmental programs that induce endogenous DSBs to promote genetic variation and correct chromosome segregation. Several crucial components in DSB repair have recently been discovered, including factors involved in DSB formation, DSB recognition, DNA end resection, and $\mathrm{dHJ}$ resolution. C. elegans research has proven to be an excellent platform to elucidate DSB repair processes in a developmental context. Its convenient germline makeup, its suitability for genetic screens, and the fact that genetic mutants are relatively easily combined have already paid off in the identification of several crucial processes during meiotic DSB repair. Although somatic DSB repair is still largely unexplored in C. elegans research, this model organism has already led to important insights into the influence of cell fate and cell cycle progression on DSB repair during development. Since many of the newly identified DSB repair genes are conserved from worms to humans and more and more tools are being developed to study DSB repair in the nematode, we expect that this little worm will contribute significantly to our understanding of DSB repair in multicellular animals.
Acknowledgments We thank Daphne Pontier for providing the pictures of germline nuclei stained against RAD-51.We are also grateful to all members of the Tijsterman lab for discussions and to Nick Johnson for helpful comments on the manuscript. We apologize to authors whose research articles could not be cited due to space constraints.

Open Access This article is distributed under the terms of the Creative Commons Attribution Noncommercial License which permits any noncommercial use, distribution, and reproduction in any medium, provided the original author(s) and source are credited.

\section{References}

Adamo A, Montemauri P, Silva N, Ward JD, Boulton SJ, La Volpe A (2008) BRC-1 acts in the inter-sister pathway of meiotic doublestrand break repair. EMBO Rep 9:287-292

Alpi A, Pasierbek P, Gartner A, Loidl J (2003) Genetic and cytological characterization of the recombination protein RAD-51 in Caenorhabditis elegans. Chromosoma 112:6-16

Andersen SL, Bergstralh DT, Kohl KP, LaRocque JR, Moore CB, Sekelsky J (2009) Drosophila MUS312 and the vertebrate ortholog BTBD12 interact with DNA structure-specific endonucleases in DNA repair and recombination. Mol Cell 35:128-135

Archambault V, Glover DM (2009) Polo-like kinases: conservation and divergence in their functions and regulation. Nat Rev Mol Cell Biol 10:265-275

Bailly AP, Freeman A, Hall J, Declais AC, Alpi A, Lilley DM, Ahmed S, Gartner A (2010) The Caenorhabditis elegans homolog of Gen1/Yen1 resolvases links DNA damage signaling to DNA double-strand break repair. PLoS Genet 6:e1001025

Barber LJ, Youds JL, Ward JD, McIlwraith MJ, O'Neil NJ, Petalcorin MI, Martin JS, Collis SJ, Cantor SB, Auclair M, Tissenbaum H, West SC, Rose AM, Boulton SJ (2008) RTEL1 maintains genomic stability by suppressing homologous recombination. Cell 135:261-271

Barchi M, Roig I, Di Giacomo M, de Rooij DG, Keeney S, Jasin M (2008) ATM promotes the obligate XY crossover and both crossover control and chromosome axis integrity on autosomes. PLoS Genet 4:e1000076

Bennett CB, Lewis AL, Baldwin KK, Resnick MA (1993) Lethality induced by a single site-specific double-strand break in a dispensable yeast plasmid. Proc Natl Acad Sci USA 90:56135617

Beucher A, Birraux J, Tchouandong L, Barton O, Shibata A, Conrad S, Goodarzi AA, Krempler A, Jeggo PA, Lobrich M (2009) ATM and Artemis promote homologous recombination of radiation-induced DNA double-strand breaks in G2. EMBO J 28:3413-3427

Bhalla N, Wynne DJ, Jantsch V, Dernburg AF (2008) ZHP-3 acts at crossovers to couple meiotic recombination with synaptonemal complex disassembly and bivalent formation in C. elegans. PLoS Genet 4:e1000235

Bickel JS, Chen L, Hayward J, Yeap SL, Alkers AE, Chan RC (2010) Structural maintenance of chromosomes (SMC) proteins promote homolog-independent recombination repair in meiosis crucial for germ cell genomic stability. PLoS Genet 6:e1001028

Boddy MN, Lopez-Girona A, Shanahan P, Interthal H, Heyer WD, Russell P (2000) Damage tolerance protein Mus81 associates with the FHA1 domain of checkpoint kinase Cds1. Mol Cell Biol 20:8758-8766

Bolderson E, Tomimatsu N, Richard DJ, Boucher D, Kumar R, Pandita TK, Burma S, Khanna KK (2010) Phosphorylation of Exo1 modulates homologous recombination repair of DNA double-strand breaks. Nucleic Acids Res 38:1821-1831 
Borner GV, Kleckner N, Hunter N (2004) Crossover/noncrossover differentiation, synaptonemal complex formation, and regulatory surveillance at the leptotene/zygotene transition of meiosis. Cell 117:29-45

Boulton SJ (2009) DNA repair: a heavyweight joins the fray. Nature 462:857-858

Boulton SJ, Martin JS, Polanowska J, Hill DE, Gartner A, Vidal M (2004) BRCA1/BARD1 orthologs required for DNA repair in Caenorhabditis elegans. Curr Biol 14:33-39

Brenner S (1974) The genetics of Caenorhabditis elegans. Genetics 77:71-94

Budd ME, Tong AH, Polaczek P, Peng X, Boone C, Campbell JL (2005) A network of multi-tasking proteins at the DNA replication fork preserves genome stability. PLoS Genet 1:e61

Buhler C, Borde V, Lichten M (2007) Mapping meiotic single-strand DNA reveals a new landscape of DNA double-strand breaks in Saccharomyces cerevisiae. PLoS Biol 5:e324

Burma S, Chen BP, Chen DJ (2006) Role of non-homologous end joining (NHEJ) in maintaining genomic integrity. DNA Repair (Amst) 5:1042-1048

Bzymek M, Thayer NH, Oh SD, Kleckner N, Hunter N (2010) Double Holliday junctions are intermediates of DNA break repair. Nature 464:937-941

Cadet J, Bellon S, Douki T, Frelon S, Gasparutto D, Muller E, Pouget JP, Ravanat JL, Romieu A, Sauvaigo S (2004) Radiation-induced DNA damage: formation, measurement, and biochemical features. J Environ Pathol Toxicol Oncol 23:33-43

Carballo JA, Cha RS (2007) Meiotic roles of Mec1, a budding yeast homolog of mammalian ATR/ATM. Chromosome Res 15:539550

Chase D, Golden A, Heidecker G, Ferris DK (2000a) Caenorhabditis elegans contains a third polo-like kinase gene. DNA Seq 11:327334

Chase D, Serafinas C, Ashcroft N, Kosinski M, Longo D, Ferris DK, Golden A (2000b) The polo-like kinase PLK-1 is required for nuclear envelope breakdown and the completion of meiosis in Caenorhabditis elegans. Genesis 26:26-41

Chen CF, Brill SJ (2007) Binding and activation of DNA topoisomerase III by the Rmil subunit. J Biol Chem 282:28971-28979

Chen PL, Chen CF, Chen Y, Xiao J, Sharp ZD, Lee WH (1998) The BRC repeats in BRCA2 are critical for RAD51 binding and resistance to methyl methanesulfonate treatment. Proc Natl Acad Sci USA 95:5287-5292

Chin GM, Villeneuve AM (2001) C. elegans mre-11 is required for meiotic recombination and DNA repair but is dispensable for the meiotic G(2) DNA damage checkpoint. Genes Dev 15:522534

Cimprich KA, Cortez D (2008) ATR: an essential regulator of genome integrity. Nat Rev Mol Cell Biol 9:616-627

Clejan I, Boerckel J, Ahmed S (2006) Developmental modulation of nonhomologous end joining in Caenorhabditis elegans. Genetics 173:1301-1317

Clerici M, Mantiero D, Lucchini G, Longhese MP (2005) The Saccharomyces cerevisiae Sae2 protein promotes resection and bridging of double strand break ends. J Biol Chem 280:3863138638

Clyne RK, Katis VL, Jessop L, Benjamin KR, Herskowitz I, Lichten M, Nasmyth K (2003) Polo-like kinase Cdc5 promotes chiasmata formation and cosegregation of sister centromeres at meiosis I. Nat Cell Biol 5:480-485

Colaiacovo MP, MacQueen AJ, Martinez-Perez E, McDonald K, Adamo A, La Volpe A, Villeneuve AM (2003) Synaptonemal complex assembly in C. elegans is dispensable for loading strand-exchange proteins but critical for proper completion of recombination. Dev Cell 5:463-474
Connolly B, Parsons CA, Benson FE, Dunderdale HJ, Sharples GJ, Lloyd RG, West SC (1991) Resolution of Holliday junctions in vitro requires the Escherichia coli ruvC gene product. Proc Natl Acad Sci USA 88:6063-6067

Couteau F, Nabeshima K, Villeneuve A, Zetka M (2004) A component of $C$. elegans meiotic chromosome axes at the interface of homolog alignment, synapsis, nuclear reorganization, and recombination. Curr Biol 14:585-592

Czornak K, Chughtai S, Chrzanowska KH (2008) Mystery of DNA repair: the role of the MRN complex and ATM kinase in DNA damage repair. J Appl Genet 49:383-396

Davies AA, Masson JY, McIlwraith MJ, Stasiak AZ, Stasiak A, Venkitaraman AR, West SC (2001) Role of BRCA2 in control of the RAD51 recombination and DNA repair protein. Mol Cell 7:273-282

de Vries SS, Baart EB, Dekker M, Siezen A, de Rooij DG, de Boer P, te Riele H (1999) Mouse MutS-like protein Msh5 is required for proper chromosome synapsis in male and female meiosis. Genes Dev 13:523-531

DeFazio LG, Stansel RM, Griffith JD, Chu G (2002) Synapsis of DNA ends by DNA-dependent protein kinase. EMBO J 21:3192-3200

Delacote F, Lopez BS (2008) Importance of the cell cycle phase for the choice of the appropriate DSB repair pathway, for genome stability maintenance: the trans-S double-strand break repair model. Cell Cycle 7:33-38

Dendouga N, Gao H, Moechars D, Janicot M, Vialard J, McGowan $\mathrm{CH}$ (2005) Disruption of murine Mus81 increases genomic instability and DNA damage sensitivity but does not promote tumorigenesis. Mol Cell Biol 25:7569-7579

Dernburg AF, McDonald K, Moulder G, Barstead R, Dresser M, Villeneuve AM (1998) Meiotic recombination in C. elegans initiates by a conserved mechanism and is dispensable for homologous chromosome synapsis. Cell 94:387-398

Edelmann W, Cohen PE, Kneitz B, Winand N, Lia M, Heyer J, Kolodner R, Pollard JW, Kucherlapati R (1999) Mammalian MutS homologue 5 is required for chromosome pairing in meiosis. Nat Genet 21:123-127

Fekairi S, Scaglione S, Chahwan C, Taylor ER, Tissier A, Coulon S, Dong MQ, Ruse C, Yates JR 3rd, Russell P, Fuchs RP, McGowan CH, Gaillard PH (2009) Human SLX4 is a Holliday junction resolvase subunit that binds multiple DNA repair/recombination endonucleases. Cell 138:78-89

Fung JC, Rockmill B, Odell M, Roeder GS (2004) Imposition of crossover interference through the nonrandom distribution of synapsis initiation complexes. Cell 116:795-802

Garcia-Muse T, Boulton SJ (2005) Distinct modes of ATR activation after replication stress and DNA double-strand breaks in Caenorhabditis elegans. EMBO J 24:4345-4355

Garcia-Muse T, Boulton SJ (2007) Meiotic recombination in Caenorhabditis elegans. Chromosome Res 15:607-621

Gartner A, Boag PR, Blackwell TK (2008) Germline survival and apoptosis. WormBook: 1-20

Gatti M, Pimpinelli S, Baker BS (1980) Relationships among chromatid interchanges, sister chromatid exchanges, and meiotic recombination in Drosophila melanogaster. Proc Natl Acad Sci USA 77:1575-1579

Goodyer W, Kaitna S, Couteau F, Ward JD, Boulton SJ, Zetka M (2008) HTP-3 links DSB formation with homolog pairing and crossing over during C. elegans meiosis. Dev Cell 14:263-274

Grabowski MM, Svrzikapa N, Tissenbaum HA (2005) Bloom syndrome ortholog HIM-6 maintains genomic stability in $C$. elegans. Mech Ageing Dev 126:1314-1321

Gravel S, Chapman JR, Magill C, Jackson SP (2008) DNA helicases Sgs1 and BLM promote DNA double-strand break resection. Genes Dev 22:2767-2772 
Hashizume R, Fukuda M, Maeda I, Nishikawa H, Oyake D, Yabuki Y, Ogata H, Ohta T (2001) The RING heterodimer BRCA1-BARD1 is a ubiquitin ligase inactivated by a breast cancer-derived mutation. J Biol Chem 276:14537-14540

Hayashi M, Chin GM, Villeneuve AM (2007) C. elegans germ cells switch between distinct modes of double-strand break repair during meiotic prophase progression. PLoS Genet 3:e191

Heyer WD, Ehmsen KT, Solinger JA (2003) Holliday junctions in the eukaryotic nucleus: resolution in sight? Trends Biochem Sci 28:548-557

Hillers KJ, Villeneuve AM (2003) Chromosome-wide control of meiotic crossing over in C. elegans. Curr Biol 13:1641-1647

Hoeijmakers JH (2009) DNA damage, aging, and cancer. N Engl J Med 361:1475-1485

Hoffenberg R (2003) Brenner, the worm and the prize. Clin Med 3:285-286

Hollingsworth NM, Brill SJ (2004) The Mus81 solution to resolution: generating meiotic crossovers without Holliday junctions. Genes Dev 18:117-125

Honma M, Zhang LS, Hayashi M, Takeshita K, Nakagawa Y, Tanaka N, Sofuni T (1997) Illegitimate recombination leading to allelic loss and unbalanced translocation in p53-mutated human lymphoblastoid cells. Mol Cell Biol 17:4774-4781

Horvitz HR (2003) Worms, life, and death (Nobel lecture). Chembiochem 4:697-711

Huen MS, Sy SM, Chen J (2009) BRCA1 and its toolbox for the maintenance of genome integrity. Nat Rev Mol Cell Biol 11:138-148

Huertas P (2010) DNA resection in eukaryotes: deciding how to fix the break. Nat Struct Mol Biol 17:11-16

Huertas P, Cortes-Ledesma F, Sartori AA, Aguilera A, Jackson SP (2008) CDK targets Sae2 to control DNA-end resection and homologous recombination. Nature 455:689-692

Hurley PJ, Bunz F (2007) ATM and ATR: components of an integrated circuit. Cell Cycle 6:414-417

Ip SC, Rass U, Blanco MG, Flynn HR, Skehel JM, West SC (2008) Identification of Holliday junction resolvases from humans and yeast. Nature 456:357-361

Jessop L, Lichten M (2008) Mus81/Mms4 endonuclease and Sgs1 helicase collaborate to ensure proper recombination intermediate metabolism during meiosis. Mol Cell 31:313-323

Johzuka K, Ogawa H (1995) Interaction of Mre11 and Rad50: two proteins required for DNA repair and meiosis-specific doublestrand break formation in Saccharomyces cerevisiae. Genetics 139:1521-1532

Kang YH, Lee CH, Seo YS (2010) Dna2 on the road to Okazaki fragment processing and genome stability in eukaryotes. Crit Rev Biochem Mol Biol 45:71-96

Keeney S, Kleckner N (1995) Covalent protein-DNA complexes at the $5^{\prime}$ strand termini of meiosis-specific double-strand breaks in yeast. Proc Natl Acad Sci USA 92:11274-11278

Keeney S, Neale MJ (2006) Initiation of meiotic recombination by formation of DNA double-strand breaks: mechanism and regulation. Biochem Soc Trans 34:523-525

Keeney S, Giroux CN, Kleckner N (1997) Meiosis-specific DNA double-strand breaks are catalyzed by Spo11, a member of a widely conserved protein family. Cell 88:375-384

Kelly KO, Dernburg AF, Stanfield GM, Villeneuve AM (2000) Caenorhabditis elegans msh-5 is required for both normal and radiation-induced meiotic crossing over but not for completion of meiosis. Genetics 156:617-630

Klein HL (1988) Different types of recombination events are controlled by the RAD1 and RAD52 genes of Saccharomyces cerevisiae. Genetics 120:367-377

Klein HL, Symington LS (2009) Breaking up just got easier to do. Cell 138:20-22
Kneitz B, Cohen PE, Avdievich E, Zhu L, Kane MF, Hou H Jr, Kolodner RD, Kucherlapati R, Pollard JW, Edelmann W (2000) MutS homolog 4 localization to meiotic chromosomes is required for chromosome pairing during meiosis in male and female mice. Genes Dev 14:1085-1097

Kurimasa A, Kumano S, Boubnov NV, Story MD, Tung CS, Peterson SR, Chen DJ (1999) Requirement for the kinase activity of human DNA-dependent protein kinase catalytic subunit in DNA strand break rejoining. Mol Cell Biol 19:3877-3884

Lee BI, Shannon M, Stubbs L, Wilson DM 3rd (1999) Expression specificity of the mouse exonuclease 1 (mExo1) gene. Nucleic Acids Res 27:4114-4120

Lee MH, Han SM, Han JW, Kim YM, Ahnn J, Koo HS (2003) Caenorhabditis elegans dna-2 is involved in DNA repair and is essential for germ-line development. FEBS Lett 555:250-256

Lee SJ, Gartner A, Hyun M, Ahn B, Koo HS (2010) The Caenorhabditis elegans Werner syndrome protein functions upstream of ATR and ATM in response to DNA replication inhibition and double-strand DNA breaks. PLoS Genet 6:e1000801

Lewis LK, Karthikeyan G, Westmoreland JW, Resnick MA (2002) Differential suppression of DNA repair deficiencies of Yeast rad50, mre11 and xrs2 mutants by EXO1 and TLC1 (the RNA component of telomerase). Genetics 160:49-62

Li X, Heyer WD (2008) Homologous recombination in DNA repair and DNA damage tolerance. Cell Res 18:99-113

Lieber MR (2010) NHEJ and its backup pathways in chromosomal translocations. Nat Struct Mol Biol 17:393-395

Llorente B, Symington LS (2004) The Mre11 nuclease is not required for $5^{\prime}$ to $3^{\prime}$ resection at multiple $\mathrm{HO}$-induced double-strand breaks. Mol Cell Biol 24:9682-9694

Lorenz A, West SC, Whitby MC (2010) The human Holliday junction resolvase GEN1 rescues the meiotic phenotype of a Schizosaccharomyces pombe mus81 mutant. Nucleic Acids Res 38:18661873

Luo G, Santoro IM, McDaniel LD, Nishijima I, Mills M, Youssoufian H, Vogel H, Schultz RA, Bradley A (2000) Cancer predisposition caused by elevated mitotic recombination in Bloom mice. Nat Genet 26:424-429

Lynn A, Soucek R, Borner GV (2007) ZMM proteins during meiosis: crossover artists at work. Chromosome Res 15:591-605

MacQueen AJ, Villeneuve AM (2001) Nuclear reorganization and homologous chromosome pairing during meiotic prophase require C. elegans chk-2. Genes Dev 15:1674-1687

Manfrini N, Guerini I, Citterio A, Lucchini G, Longhese MP (2010) Processing of meiotic DNA double strand breaks requires cyclindependent kinase and multiple nucleases. J Biol Chem 285:11628-11637

Martin JS, Winkelmann N, Petalcorin MI, McIlwraith MJ, Boulton SJ (2005) RAD-51-dependent and -independent roles of a Caenorhabditis elegans BRCA2-related protein during DNA doublestrand break repair. Mol Cell Biol 25:3127-3139

Martinez-Perez E, Villeneuve AM (2005) HTP-1-dependent constraints coordinate homolog pairing and synapsis and promote chiasma formation during $C$. elegans meiosis. Genes Dev 19:2727-2743

Matsuoka S, Ballif BA, Smogorzewska A, McDonald ER 3rd, Hurov KE, Luo J, Bakalarski CE, Zhao Z, Solimini N, Lerenthal Y, Shiloh Y, Gygi SP, Elledge SJ (2007) ATM and ATR substrate analysis reveals extensive protein networks responsive to DNA damage. Science 316:1160-1166

Mazin AV, Mazina OM, Bugreev DV, Rossi MJ (2010) Rad54, the motor of homologous recombination. DNA Repair (Amst) 9:286-302

McKee AH, Kleckner N (1997) A general method for identifying recessive diploid-specific mutations in Saccharomyces cerevisiae, 
its application to the isolation of mutants blocked at intermediate stages of meiotic prophase and characterization of a new gene SAE2. Genetics 146:797-816

McPherson JP, Lemmers B, Chahwan R, Pamidi A, Migon E, MatysiakZablocki E, Moynahan ME, Essers J, Hanada K, Poonepalli A, Sanchez-Sweatman O, Khokha R, Kanaar R, Jasin M, Hande MP, Hakem R (2004) Involvement of mammalian Mus81 in genome integrity and tumor suppression. Science 304:1822-1826

McVey M, Lee SE (2008) MMEJ repair of double-strand breaks (director's cut): deleted sequences and alternative endings. Trends Genet 24:529-538

Meier B, Barber LJ, Liu Y, Shtessel L, Boulton SJ, Gartner A, Ahmed S (2009) The MRT-1 nuclease is required for DNA crosslink repair and telomerase activity in vivo in Caenorhabditis elegans. EMBO J 28:3549-3563

Mets DG, Meyer BJ (2009) Condensins regulate meiotic DNA break distribution, thus crossover frequency, by controlling chromosome structure. Cell 139:73-86

Milman N, Higuchi E, Smith GR (2009) Meiotic DNA double-strand break repair requires two nucleases, MRN and Ctp1, to produce a single size class of Rec12 (Spo11)-oligonucleotide complexes. Mol Cell Biol 29:5998-6005

Mimitou EP, Symington LS (2008) Sae2, Exo1 and Sgs1 collaborate in DNA double-strand break processing. Nature 455:770-774

Moreau S, Morgan EA, Symington LS (2001) Overlapping functions of the Saccharomyces cerevisiae Mre11, Exo1 and Rad27 nucleases in DNA metabolism. Genetics 159:1423-1433

Mortimer RK, Contopoulou CR, King JS (1992) Genetic and physical maps of Saccharomyces cerevisiae, Edition 11. Yeast 8:817-902

Moynahan ME, Pierce AJ, Jasin M (2001) BRCA2 is required for homology-directed repair of chromosomal breaks. Mol Cell 7:263-272

Munoz IM, Hain K, Declais AC, Gardiner M, Toh GW, SanchezPulido L, Heuckmann JM, Toth R, Macartney T, Eppink B, Kanaar R, Ponting CP, Lilley DM, Rouse J (2009) Coordination of structure-specific nucleases by human SLX4/BTBD12 is required for DNA repair. Mol Cell 35:116-127

Munz P (1994) An analysis of interference in the fission yeast Schizosaccharomyces pombe. Genetics 137:701-707

Nasmyth K, Haering CH (2009) Cohesin: its roles and mechanisms. Annu Rev Genet 43:525-558

Nimonkar AV, Ozsoy AZ, Genschel J, Modrich P, Kowalczykowski SC (2008) Human exonuclease 1 and BLM helicase interact to resect DNA and initiate DNA repair. Proc Natl Acad Sci USA 105:16906-16911

Ogawa H, Johzuka K, Nakagawa T, Leem SH, Hagihara AH (1995) Functions of the yeast meiotic recombination genes, MRE11 and MRE2. Adv Biophys 31:67-76

Oh SD, Lao JP, Taylor AF, Smith GR, Hunter N (2008) RecQ helicase, Sgs1, and XPF family endonuclease, Mus81-Mms4, resolve aberrant joint molecules during meiotic recombination. Mol Cell 31:324-336

O'Neil N, Rose A (2006) DNA repair. WormBook: 1-12

Osman F, Adriance M, McCready S (2000) The genetic control of spontaneous and UV-induced mitotic intrachromosomal recombination in the fission yeast Schizosaccharomyces pombe. Curr Genet 38:113-125

Osman F, Dixon J, Doe CL, Whitby MC (2003) Generating crossovers by resolution of nicked Holliday junctions: a role for Mus81Eme1 in meiosis. Mol Cell 12:761-774

Pan X, Ye P, Yuan DS, Wang X, Bader JS, Boeke JD (2006) A DNA integrity network in the yeast Saccharomyces cerevisiae. Cell 124:1069-1081

Pannicke U, Ma Y, Hopfner KP, Niewolik D, Lieber MR, Schwarz K (2004) Functional and biochemical dissection of the structurespecific nuclease ARTEMIS. EMBO J 23:1987-1997
Pasierbek P, Jantsch M, Melcher M, Schleiffer A, Schweizer D, Loidl J (2001) A Caenorhabditis elegans cohesion protein with functions in meiotic chromosome pairing and disjunction. Genes Dev 15:1349-1360

Penkner A, Portik-Dobos Z, Tang L, Schnabel R, Novatchkova M, Jantsch V, Loidl J (2007) A conserved function for a Caenorhabditis elegans Com1/Sae2/CtIP protein homolog in meiotic recombination. EMBO J 26:5071-5082

Penkner AM, Fridkin A, Gloggnitzer J, Baudrimont A, Machacek T, Woglar A, Csaszar E, Pasierbek P, Ammerer G, Gruenbaum Y, Jantsch V (2009) Meiotic chromosome homology search involves modifications of the nuclear envelope protein Matefin/ SUN-1. Cell 139:920-933

Petalcorin MI, Sandall J, Wigley DB, Boulton SJ (2006) CeBRC-2 stimulates D-loop formation by RAD-51 and promotes DNA single-strand annealing. J Mol Biol 361:231-242

Petalcorin MI, Galkin VE, Yu X, Egelman EH, Boulton SJ (2007) Stabilization of RAD-51-DNA filaments via an interaction domain in Caenorhabditis elegans BRCA2. Proc Natl Acad Sci USA 104:8299-8304

Phillips CM, Meng X, Zhang L, Chretien JH, Urnov FD, Dernburg AF (2009) Identification of chromosome sequence motifs that mediate meiotic pairing and synapsis in C. elegans. Nat Cell Biol 11:934-942

Plank JL, Wu J, Hsieh TS (2006) Topoisomerase III alpha and Bloom's helicase can resolve a mobile double Holliday junction substrate through convergent branch migration. Proc Natl Acad Sci USA 103:11118-11123

Polanowska J, Martin JS, Garcia-Muse T, Petalcorin MI, Boulton SJ (2006) A conserved pathway to activate BRCA1-dependent ubiquitylation at DNA damage sites. EMBO J 25:2178-2188

Polo SE, Kaidi A, Baskcomb L, Galanty Y, Jackson SP (2010) Regulation of DNA-damage responses and cell-cycle progression by the chromatin remodelling factor CHD4. EMBO J 29:3130 3139.

Pontier DB, Tijsterman M (2009) A robust network of double-strand break repair pathways governs genome integrity during $C$. elegans development. Curr Biol 19:1384-1388

Pothof J, van Haaften G, Thijssen K, Kamath RS, Fraser AG, Ahringer J, Plasterk RH, Tijsterman M (2003) Identification of genes that protect the $C$. elegans genome against mutations by genome-wide RNAi. Genes Dev 17:443-448

Prado F, Aguilera A (1995) Role of reciprocal exchange, one-ended invasion crossover and single-strand annealing on inverted and direct repeat recombination in yeast: different requirements for the RAD1, RAD10, and RAD52 genes. Genetics 139:109-123

Prinz S, Amon A, Klein F (1997) Isolation of COM1, a new gene required to complete meiotic double-strand break-induced recombination in Saccharomyces cerevisiae. Genetics 146:781-795

Reddy KC, Villeneuve AM (2004) C. elegans HIM-17 links chromatin modification and competence for initiation of meiotic recombination. Cell 118:439-452

Reid LJ, Shakya R, Modi AP, Lokshin M, Cheng JT, Jasin M, Baer R, Ludwig T (2008) E3 ligase activity of BRCA1 is not essential for mammalian cell viability or homology-directed repair of doublestrand DNA breaks. Proc Natl Acad Sci USA 105:20876-20881

Rockmill B, Fung JC, Branda SS, Roeder GS (2003) The Sgs1 helicase regulates chromosome synapsis and meiotic crossing over. Curr Biol 13:1954-1962

Rossi ML, Ghosh AK, Bohr VA (2010) Roles of Werner syndrome protein in protection of genome integrity. DNA Repair (Amst) 9:331-344

Rupnik A, Lowndes NF, Grenon M (2010) MRN and the race to the break. Chromosoma 119:115-135

Saito TT, Youds JL, Boulton SJ, Colaiacovo MP (2009) Caenorhabditis elegans HIM-18/SLX-4 interacts with SLX-1 and XPF-1 
and maintains genomic integrity in the germline by processing recombination intermediates. PLoS Genet 5:e1000735

Sato A, Isaac B, Phillips CM, Rillo R, Carlton PM, Wynne DJ, Kasad RA, Dernburg AF (2009) Cytoskeletal forces span the nuclear envelope to coordinate meiotic chromosome pairing and synapsis. Cell 139:907-919

Severson AF, Ling L, van Zuylen V, Meyer BJ (2009) The axial element protein HTP-3 promotes cohesin loading and meiotic axis assembly in C. elegans to implement the meiotic program of chromosome segregation. Genes Dev 23:1763-1778

Sharples GJ, Lloyd RG (1991) Resolution of Holliday junctions in Escherichia coli: identification of the ruvC gene product as a 19kilodalton protein. J Bacteriol 173:7711-7715

Shinohara M, Gasior SL, Bishop DK, Shinohara A (2000) Tid1/ Rdh54 promotes colocalization of rad51 and dmc1 during meiotic recombination. Proc Natl Acad Sci USA 97:1081410819

Smeenk G, Wiegant WW, Vrolijk H, Solari AP, Pastink A, van Attikum H (2010) The NuRD chromatin-remodeling complex regulates signaling and repair of DNA damage. J Cell Biol 190:741-749.

Smolikov S, Eizinger A, Schild-Prufert K, Hurlburt A, McDonald K, Engebrecht J, Villeneuve AM, Colaiacovo MP (2007) SYP-3 restricts synaptonemal complex assembly to bridge paired chromosome axes during meiosis in Caenorhabditis elegans. Genetics 176:2015-2025

Smolikov S, Schild-Prufert K, Colaiacovo MP (2008) CRA-1 uncovers a double-strand break-dependent pathway promoting the assembly of central region proteins on chromosome axes during C. elegans meiosis. PLoS Genet 4:e1000088

Smolka MB, Albuquerque CP, Chen SH, Zhou H (2007) Proteomewide identification of in vivo targets of DNA damage checkpoint kinases. Proc Natl Acad Sci USA 104:10364-10369

Snowden T, Acharya S, Butz C, Berardini M, Fishel R (2004) hMSH4-hMSH5 recognizes Holliday junctions and forms a meiosis-specific sliding clamp that embraces homologous chromosomes. Mol Cell 15:437-451

Solinger JA, Heyer WD (2001) Rad54 protein stimulates the postsynaptic phase of Rad51 protein-mediated DNA strand exchange. Proc Natl Acad Sci USA 98:8447-8453

Sourirajan A, Lichten M (2008) Polo-like kinase Cdc5 drives exit from pachytene during budding yeast meiosis. Genes Dev 22:2627-2632

Sugawara N, Ira G, Haber JE (2000) DNA length dependence of the single-strand annealing pathway and the role of Saccharomyces cerevisiae RAD59 in double-strand break repair. Mol Cell Biol 20:5300-5309

Sulston JE (2003) Caenorhabditis elegans: the cell lineage and beyond (Nobel lecture). Chembiochem 4:688-696

Sulston JE, Schierenberg E, White JG, Thomson JN (1983) The embryonic cell lineage of the nematode Caenorhabditis elegans. Dev Biol 100:64-119

Svendsen JM, Smogorzewska A, Sowa ME, O'Connell BC, Gygi SP, Elledge SJ, Harper JW (2009) Mammalian BTBD12/SLX4 assembles a Holliday junction resolvase and is required for DNA repair. Cell 138:63-77

Szostak JW, Orr-Weaver TL, Rothstein RJ, Stahl FW (1983) The doublestrand-break repair model for recombination. Cell 33:25-35

Tang L, Machacek T, Mamnun YM, Penkner A, Gloggnitzer J, Wegrostek C, Konrat R, Jantsch MF, Loidl J, Jantsch V (2010) Mutations in Caenorhabditis elegans him-19 show meiotic defects that worsen with age. Mol Biol Cell 21:885-896

Tay YD, Wu L (2010) Overlapping roles for Yen1 and Mus81 in cellular Holliday junction processing. J Biol Chem 285:11427-11432
Tran PT, Erdeniz N, Symington LS, Liskay RM (2004) EXO1-a multitasking eukaryotic nuclease. DNA Repair (Amst) 3:1549-1559

Tsai CJ, Mets DG, Albrecht MR, Nix P, Chan A, Meyer BJ (2008) Meiotic crossover number and distribution are regulated by a dosage compensation protein that resembles a condensin subunit. Genes Dev 22:194-211

van Haaften G, Romeijn R, Pothof J, Koole W, Mullenders LH, Pastink A, Plasterk RH, Tijsterman M (2006) Identification of conserved pathways of DNA-damage response and radiation protection by genome-wide RNAi. Curr Biol 16:1344-1350

Venkitaraman AR (2001) Chromosome stability, DNA recombination and the BRCA2 tumour suppressor. Curr Opin Cell Biol 13:338343.

Vilenchik MM, Knudson AG (2006) Radiation dose-rate effects, endogenous DNA damage, and signaling resonance. Proc Natl Acad Sci USA 103:17874-17879

Ward JD, Barber LJ, Petalcorin MI, Yanowitz J, Boulton SJ (2007) Replication blocking lesions present a unique substrate for homologous recombination. EMBO J 26:3384-3396

Ward JD, Muzzini DM, Petalcorin MI, Martinez-Perez E, Martin JS, Plevani P, Cassata G, Marini F, Boulton SJ (2010) Overlapping mechanisms promote postsynaptic RAD-51 filament disassembly during meiotic double-strand break repair. Mol Cell 37:259272

West SC (2009) The search for a human Holliday junction resolvase. Biochem Soc Trans 37:519-526

Whitby MC (2005) Making crossovers during meiosis. Biochem Soc Trans 33:1451-1455

Wicky C, Alpi A, Passannante M, Rose A, Gartner A, Muller F (2004) Multiple genetic pathways involving the Caenorhabditis elegans Bloom's syndrome genes him- 6 , rad-51, and top- 3 are needed to maintain genome stability in the germ line. Mol Cell Biol 24:5016-5027

Winand NJ, Panzer JA, Kolodner RD (1998) Cloning and characterization of the human and Caenorhabditis elegans homologs of the Saccharomyces cerevisiae MSH5 gene. Genomics 53:69-80

Wood WB (1988) The Nematode Caenorhabditis elegans. Cold Spring Harbor Laboratory Press

Wu L, Hickson ID (2003) The Bloom's syndrome helicase suppresses crossing over during homologous recombination. Nature 426:870 874

Youds JL, Mets DG, McIlwraith MJ, Martin JS, Ward JD, ON NJ, Rose AM, West SC, Meyer BJ, Boulton SJ (2010) RTEL-1 enforces meiotic crossover interference and homeostasis. Science 327:1254-1258

Yuan SS, Lee SY, Chen G, Song M, Tomlinson GE, Lee EY (1999) BRCA2 is required for ionizing radiation-induced assembly of Rad51 complex in vivo. Cancer Res 59:3547-3551

Yun MH, Hiom K (2009) CtIP-BRCA1 modulates the choice of DNA double-strand-break repair pathway throughout the cell cycle. Nature 459:460-463

Zalevsky J, MacQueen AJ, Duffy JB, Kemphues KJ, Villeneuve AM (1999) Crossing over during Caenorhabditis elegans meiosis requires a conserved MutS-based pathway that is partially dispensable in budding yeast. Genetics 153:1271-1283

Zetka MC, Kawasaki I, Strome S, Muller F (1999) Synapsis and chiasma formation in Caenorhabditis elegans require HIM-3, a meiotic chromosome core component that functions in chromosome segregation. Genes Dev 13:2258-2270

Zhu Z, Chung WH, Shim EY, Lee SE, Ira G (2008) Sgs 1 helicase and two nucleases Dna2 and Exo1 resect DNA double-strand break ends. Cell 134:981-994

Zickler D (2006) From early homologue recognition to synaptonemal complex formation. Chromosoma 115:158-174 